\title{
RESÍDUOS DE AGROTÓXICOS EM ALIMENTOS: UMA PREOCUPAÇÃO AMBIENTAL GLOBAL - UM ENFOQUE ÀS MAÇÃS
}

\author{
Isabel Cristina Sales Fontes Jardim* e Juliano de Almeida Andrade \\ Departamento de Química Analítica, Instituto de Química, Universidade Estadual de Campinas, CP 6154, 13083-970 \\ Campinas - SP, Brasil \\ Sonia Claudia do Nascimento de Queiroz \\ Embrapa Meio Ambiente, Rodovia SP 340 - km 127,5, 13820-000 Jaguariúna - SP, Brasil
}

Recebido em 18/2/08; aceito em 19/11/08; publicado na web em 15/4/09

\begin{abstract}
RESIDUES OF PESTICIDES IN FOOD: A GLOBAL ENVIRONMENTAL PREOCCUPATION - FOCUSSING ON APPLES.
This paper describes the use of pesticides in agriculture. Research has shown that significant quantities of pesticide residues have been found in many types of foods. Thus, an overview is given of pesticide residue determinations in fruits and vegetables, with special attention to apples. The toxicity and the adverse effects possibly caused by the exposure of these compounds are alerting the scientific community to develop studies about the validation of analytical methods for multiresidue pesticide determination in these samples. This review shows that pesticide-residue determination in apples is becoming a very important and challenging issue.
\end{abstract}

Keywords: pesticides; apples; multiresidue analysis in food.

\section{INTRODUÇÃO}

O crescimento da população mundial observado nas últimas décadas, acompanhado do desenvolvimento tecnológico e da migração de pessoas da zona rural para a urbana, têm trazido várias desvantagens aos ecossistemas. Dentre os principais fatores observados destaca-se a competição existente entre as atividades dos setores urbano, agrícola e pecuário, que tem causado consequências drásticas ao meio ambiente, especialmente, à agricultura. Por um lado, com o crescimento urbano observa-se uma diminuição das áreas apropriadas ao cultivo agrícola, por outro, esse crescimento da população em conjunto com o consumo e a demanda de produtos alimentícios vêm exigindo a utilização, cada vez maior, de produtos químicos em áreas de cultivo agrícola. Essa demanda de produtos e serviços pela sociedade, ocorrida de certa forma natural, vem sendo observada desde períodos históricos, como o período Colonial. Porém, em particular, essa exigência esboçou-se com maior significância no início do período da Revolução Industrial, no século XVIII, acentuando-se nos séculos seguintes.

A crescente procura e consequente produção e utilização de novos produtos pela sociedade moderna têm como principais consequências a geração e o acúmulo de compostos químicos indesejáveis no meio ambiente. No Brasil, por exemplo, isso pode ser evidenciado facilmente pela comprovação de grandes quantidades de passivos ambientais registrados até o momento e, também, pelo aumento do número de áreas contaminadas, como mostra o último relatório publicado pela Companhia de Tecnologia de Saneamento Ambiental (CETESB) sobre as áreas contaminadas no estado de São Paulo. ${ }^{1}$

A origem dessas áreas contaminadas e do passivo ambiental existente está relacionada, principalmente, com o desconhecimento, em épocas passadas, de procedimentos seguros para o manejo de substâncias perigosas. Outros possíveis fatores responsáveis pelo aparecimento dessas áreas é o desrespeito aos procedimentos seguros e, também, a ocorrência de acidentes ou vazamentos durante o

\footnotetext{
*e-mail: icsfj@iqm.unicamp.br
}

desenvolvimento de processos produtivos, de transporte ou de armazenamento de matérias-primas e de produtos. Sabe-se que, de forma global, a existência de uma área contaminada pode gerar inúmeros problemas à sociedade, como danos à saúde pública, comprometimento da qualidade dos recursos hídricos utilizados para o consumo humano, restrições ao uso do solo e, até mesmo, danos ao patrimônio público e privado com a desvalorização das propriedades, além de danos ao meio ambiente. ${ }^{1}$

Em face ao exposto, em maio de 2002, a CETESB divulgou, pela primeira vez, a lista de áreas contaminadas, registrando a existência de 255 áreas contaminadas somente no estado de São Paulo. O registro das áreas contaminadas vem sendo constantemente modificado e, após 7 atualizações (outubro/2003, novembro/ 2004, maio/2005, novembro/2005, maio/2006, novembro/2006 e novembro/2007), constatou-se a contaminação de 2.272 áreas até o final de $2007 .{ }^{1}$ Nesta conjuntura, o aumento do número de sítios contaminados pode ser atribuído às atividades antrópicas, como a aplicação de agrotóxicos.

Normalmente, compostos orgânicos dispostos na natureza pelo homem podem sofrer modificações estruturais, como variações no número de átomos de carbono e alterações nas quantidades e nos tipos dos grupos funcionais originalmente presentes nas moléculas precursoras. Assim, o conhecimento da natureza química dos grupos funcionais de cada contaminante é especialmente significante, pois a presença e a conformação estrutural desses grupos na molécula, em geral, determinam características químicas extremamente importantes para o entendimento do processo de contaminação como um todo. $\mathrm{O}$ estudo das características físicas, químicas e biológicas, intrínsecas de cada composto e de cada matriz, torna-se passível à identificação de informações sobre a reatividade, toxicidade e mobilidade desses compostos nos diferentes compartimentos ambientais. Estas informações são decisivas na tomada de decisão para se remediar ou revitalizar um sítio contaminado. Além disso, todos esses parâmetros estão associados diretamente aos riscos de contaminação causados aos seres humanos pela exposição a essas substâncias. ${ }^{2}$

Em suma, compostos orgânicos, como os agrotóxicos, fazem parte de algumas classes de substâncias químicas que são consideradas 
potencialmente tóxicas aos seres humanos. Conforme observado por Schwarzenbach et al., ${ }^{3}$ dentre estes compostos, vários têm como características principais hidrofobicidade elevada e reatividade baixa no meio ambiente. Essas características justificam a tendência desses compostos em se acumularem ou bioconcentrarem nos tecidos dos organismos vivos. A falta de uma via eficiente para a degradação desses compostos, em combinação com a sua hidrofobicidade, tem levado ao seu acúmulo em organismos vivos, incluindo peixes, seres humanos e outros animais.

Não obstante a existência de efeitos ambientalmente indesejáveis com a utilização de agrotóxicos, o uso desses compostos em vários estágios do cultivo de alimentos, incluindo as etapas pós-colheita ocorridas durante o armazenamento do produto, exerce um papel importante na proteção e na preservação de alimentos. Entretanto, salienta-se que o monitoramento consciencioso e completo de resíduos de agrotóxicos em alimentos é crucial para a avaliação dos riscos advindos de uma determinada via de exposição em um organismo, por um período de tempo. Por isso, a realização de um programa nacional de monitoramento de resíduos de agrotóxicos em alimentos é imprescindível para que ações da vigilância sanitária, com foco na prevenção e no controle dos riscos à saúde decorrentes do consumo de alimentos contaminados, sejam colocadas em prática.

O estabelecimento e a regulamentação de limites máximos de resíduos (LMR) em alimentos por agências governamentais de diversos países e pela comissão da União Européia têm se tornado mais frequente na última década. Esses procedimentos, em geral, visam garantir a segurança do consumidor e a regulamentação do comércio externo. ${ }^{4-9}$ No Brasil, a Agência Nacional de Vigilância Sanitária (ANVISA), do Ministério da Saúde, é o órgão responsável que estabelece os LMR para diversos tipos de alimentos comercializados no país (ver detalhes desse assunto no item "Legislação ambiental").

Considerando principalmente o número elevado de resíduos de agrotóxicos encontrados em alimentos, ${ }^{10,11}$ atualmente observa-se uma tendência na realização de trabalhos científicos, com pesquisas que envolvem o desenvolvimento, a otimização e validação de métodos analíticos. Estes métodos são empregados, não somente para determinar uma ou duas substâncias na matriz de interesse, mas sim, para a determinação simultânea de muitos compostos de classes diferentes em uma única análise, denominada de "determinação de multirresíduos de agrotóxicos". Neste caso, pode-se destacar o trabalho desenvolvido por Hirahara et al. ${ }^{12}$ que consistiu na análise de 12 tipos diferentes de amostras, entre elas, frutas, verduras e chás. Neste trabalho, os autores utilizaram um método multirresíduo, que foi otimizado e validado, para a determinação de 140 tipos de agrotóxicos, aplicados nas amostras estudadas.

Dentre os procedimentos analíticos empregados na determinação de multirresíduos de agrotóxicos, a extração dos analitos é considerada uma das etapas laboratoriais mais importante, realizada antes da determinação de um composto em uma amostra ambiental. Assim como o método multirresíduo, a extração dos compostos deve ser acompanhada do desenvolvimento e da otimização das condições experimentais, para cada matriz estudada. Numerosos métodos de extração de agrotóxicos em frutas e verduras usando particionamento de solventes, ${ }^{13,14}$ microextração em fase sólida (Solid-Phase Microextraction - SPME), ${ }^{15}$ extração em fase sólida (Solid-Phase Extraction - SPE), ${ }^{16-18}$ extração líquido-líquido (Liquid-Liquid Extraction - LLE), dispersão da matriz em fase sólida (Matrix Solid-Phase Dispersion-MSPD) ${ }^{19-23}$ e extração em ponto nuvem (Cloud Point Extraction - CPE) ${ }^{24,25}$ são encontrados na literatura. Além destes, um método denominado QuEChERS (Quick, Easy, Cheap, Effective, Rugged and Safe) vem sendo aplicado para a extração de multirresíduos de agrotóxicos. Esse método foi desenvolvido inicialmente por Anastassiades et al..$^{26} \mathrm{e}$, resumidamente, envolve a extração dos analitos da amostra com acetonitrila contendo $1 \%$ de ácido acético, seguida da partição líquido-líquido com a adição de sulfato de magnésio anidro e acetato de sódio. O método tem sido empregado por diversos pesquisadores ${ }^{27-31} \mathrm{e}$ é reconhecido como sendo de fácil utilização, rápido, de baixo custo e bastante eficiente na extração de multirresíduos de agrotóxicos na análise de alimentos.

Existem muitos métodos multirresíduos descritos na literatura, os quais permitem a determinação simultânea de um número extenso de agrotóxicos em alimentos em níveis muito baixos de concentração. Em muitos casos, a cromatografia gasosa (CG) tem sido a técnica selecionada para a análise desses compostos em frutas e verduras. ${ }^{32}$ Entretanto, nos últimos anos, pode-se observar uma tendência para o uso de agrotóxicos mais polares, os quais apresentam menor persistência e toxicidade que os apolares. Os compostos polares iônicos são menos adequados para análise usando CG e isto implica no uso de técnicas alternativas, como a cromatografia líquida de alta eficiência (CLAE) ${ }^{33} \mathrm{~A}$ cromatografia líquida acoplada à espectrometria de massas (CL-EM) é uma das técnicas mais poderosas para a análise de resíduos de agrotóxicos polares iônicos, de baixa volatilidade ou instabilidade térmica. A CLé muito efetiva na separação dos analitos, enquanto a EM permite a sua identificação e/ou confirmação em nível de traços. Instrumentos modernos de CL-EM empregando ionização à pressão atmosférica provêm excelentes seletividade e detectabilidade, que habilitam análises dos compostos-alvo em níveis de traços. ${ }^{34}$

Recentemente, o acoplamento CL em série com o espectrômetro de massas (CL-EM-EM) está gradualmente se tornando importante para análise de resíduos de agrotóxicos em frutas e verduras. O monitoramento dos produtos da fragmentação secundária permite uma discriminação muito maior dos interferentes da matriz que o uso dos produtos de fragmentação primária (EM). De fato, esta técnica permite a análise de agrotóxicos em níveis de ultra-traços (da ordem de ng kg-1 ou menor), mesmo na presença de interferentes. A fragmentação controlada da EM é uma ferramenta essencial para a identificação confiável do analito de interesse com maior seletividade; além disso, essa fragmentação gera sinais mais limpos melhorando a razão sinal/ruído e diminuindo, portanto, os limites de detecção e quantificação. Neste sentido, as técnicas CG-EMEM e CL-EM-EM têm sido consideradas como sendo as mais modernas e avançadas em análises de resíduos de agrotóxicos. ${ }^{35-38}$ Por esses motivos, Rawn et al. ${ }^{39}$ afirmam que os métodos analíticos empregados na determinação de agrotóxicos em alimentos devem ser capazes de quantificá-los em níveis baixos de concentrações e, além disso, confirmar, de forma precisa, rápida, eficiente e segura, a identidade de qualquer resíduo detectado.

Atualmente, observa-se um aumento considerável e constante no consumo de frutas, especialmente o de maçãs. ${ }^{40-42}$ Esse aumento do consumo de maçãs pode ser atribuído, praticamente, a dois fatores: por ser um alimento de acesso fácil à população e, aos benefícios que esse alimento proporciona à saúde humana. ${ }^{43-57}$ Entretanto, as pesquisas recentes revelam que as maçãs, principalmente as comercializadas e consumidas in natura, expõem as pessoas que as consomem, aumentando os riscos de contaminação por resíduos de agrotóxicos, podendo afetar diretamente a saúde.$^{58-67}$ Embora alguns resíduos de agrotóxicos encontrados nesses alimentos não excedam os limites máximos permitidos para o consumo humano, ainda não se conhecem exatamente os efeitos da acumulação, ao longo do tempo, desses compostos no organismo. O que se conhece até o momento é que muitos agrotóxicos podem causar câncer ou outros efeitos adversos em humanos. Portanto, considerando que até o momento não há estudos sobre os efeitos da exposição crônica a essas substâncias, associada ao consumo elevado de maçãs e às quantidades significativas de agrotóxicos aplicadas nessas frutas, conforme tem revelado 
a literatura científica, essa temática será abordada mais notadamente no presente artigo.

Por conseguinte, tendo em vista as considerações mencionadas, a presente revisão apresentará discussões centradas em pesquisas com enfoque à contaminação do meio ambiente e de alimentos por agrotóxicos, ressaltando, sobretudo, a contaminação de maçãs. Este artigo tem como objetivos gerais: apresentar uma revisão histórica, recente e atual, da utilização de agrotóxicos em diversos setores da sociedade; fornecer informações sobre as classificações, o consumo, a persistência e as legislações vigentes dessas substâncias; elucidar os principais fatores que têm motivado as pesquisas envolvendo a contaminação de alimentos por agrotóxicos, dando enfoque à produção do fruto da macieira no Brasil, divulgando a problemática ambiental vivenciada em nosso país e, alertar a comunidade científica sobre a importância do desenvolvimento e da validação de métodos analíticos para a determinação de multirresíduos de agrotóxicos em alimentos, apresentando, dentre outros fatores, os agrotóxicos de uso permitido mais utilizados na produção nacional de maçãs.

É importante ressaltar que, no Brasil, a adoção dos termos agrotóxicos, biocidas, defensivos agrícolas, pesticidas, praguicidas e produtos fitossanitários tem sido marcada por polêmicas e controvérsias há anos. No Brasil, a Lei Federal no. 7.802 de 11 de julho de $1989,{ }^{68}$ conhecida como "Lei de Agrotóxicos", foi regulamentada pelos Decretos nos. 98.816 de $1990^{69}$ e 4.074 de $2002,{ }^{70}$ e dispõe sobre a pesquisa, experimentação, produção, embalagem e rotulagem, o transporte, armazenamento, a comercialização, propaganda comercial, utilização, importação, exportação, o destino final dos resíduos e das embalagens, o registro, a classificação, o controle, a inspeção e fiscalização de agrotóxicos. A legislação federal brasileira, através dessa Lei, adota e define o termo "agrotóxico" para ser utilizado em todos os casos, substituindo os demais termos citados acima. Dessa forma, o termo "agrotóxico" é utilizado neste artigo e refere-se às diferentes categorias de uso, como inseticidas, herbicidas e fungicidas, dentre outras existentes. Como padronização, sugere-se que o referido termo também seja adotado por outros autores nos próximos trabalhos publicados na literatura científica nacional.

\section{AGROTÓXICOS}

\section{História dos agrotóxicos}

O uso mais antigo de agrotóxicos que se tem registro, cerca do ano 1200 a.C. (antes de Cristo), envolveu a utilização de sal e de cinzas em campos conquistados por exércitos bíblicos, para tornar as terras improdutivas. Esse, provavelmente, foi o primeiro emprego de herbicidas não seletivos. O segundo registro, datado por volta do ano 1000 a.C., foi relatado pelo poeta Homero que escreveu sobre a queima de enxofre para fumigar os lares gregos. ${ }^{71}$ Essa substância atua como inseticida e penetra nos insetos por inalação. $\mathrm{O}$ uso de $\mathrm{SO}_{2}$ procedente da combustão do enxofre sólido, às vezes mediante a incorporação do elemento em velas, continuou, pelo menos, até o século XIX. O próprio enxofre, na forma de pó ou em aerossol, foi também utilizado como inseticida e fungicida; sendo ainda usado, nos dias de hoje, por sua ação importante contra o míldio pulverulento das plantas. O míldio, também conhecido como Oídios, é um tipo de doença de planta causada por fungos altamente evoluídos do ponto de vista genético, sendo todos parasitas biotróficos obrigatórios, ou seja, só crescem no tecido vivo das plantas. Embora raramente causem a morte do vegetal, a ação desses fungos reduz o potencial produtivo das culturas e pode afetar a qualidade do produto cultivado. No ano 100 a.C. os romanos aplicaram Helleborus, que é um gênero botânico da família Ranunculaceae e que compreende cerca de 20 espécies, sendo a maioria venenosa, para o controle de ratos e insetos. ${ }^{71,72}$
Na era d.C. (depois de Cristo), um dos primeiros e mais importantes registros do uso de agrotóxicos foi datado no ano 900, quando os chineses usaram arsênio para controlar insetos em jardins. $\mathrm{O}$ uso de óleo mineral também foi relatado por Marco Pólo, no ano 1300, cuja finalidade era combater sarnas em camelos. ${ }^{72}$ Por volta dos séculos XV e XVI, o arsênio voltou a ser utilizado, além de outros elementos químicos como o mercúrio, sendo ambos empregados no combate de pragas em plantações. Na metade do século XVII, a rotenona, que é uma substância natural extraída das raízes de algumas plantas leguminosas tropicais, foi usada para paralisar peixes na América do Sul. Em 1669, ocorreu o primeiro relato do uso de arsênio como inseticida pela sociedade ocidental, em que o mel contaminado com esse composto era utilizado como isca para formigas. Em 1690, extratos de tabaco eram utilizados como inseticidas de contato. $\mathrm{O}$ tabaco voltou a ser utilizado em 1773, quando o sulfato de nicotina, extraído por aquecimento, era fumigado em plantas infestadas por insetos. ${ }^{73} \mathrm{O}$ gás cianeto de hidrogênio, $\mathrm{HCN}$, também foi usado como substância para fumigação. O seu emprego para evitar danos em peças expostas em museus foi registrado no ano 1877, sendo que alguns anos depois esse composto foi utilizado para controlar insetos em árvores frutíferas. Aproximadamente nessa década, alguns derivados de fluoretos inorgânicos, como o fluoreto de sódio, $\mathrm{NaF}$, também foram utilizados para o mesmo fim e para controlar as populações de formigas em prédios. Tanto o fluoreto de sódio quanto o ácido bórico foram empregados para eliminar baratas em edifícios infestados. Vários óleos, derivados do petróleo ou de fontes animais, como os oriundos de peixes e baleias, têm sido usados, há centenas de anos, como inseticidas e como aerossóis paralisantes para eliminar ovos de insetos. O uso do arsênio e de seus derivados no controle de insetos em jardins teve início na época dos romanos, sendo empregado pelos chineses até a Segunda Guerra Mundial. O "Verde de Paris", por exemplo, que é um sal de cobre que contém o íon arsenito, $\mathrm{AsO}_{3}^{3-}$, foi um inseticida de uso popular introduzido nos Estados Unidos em 1867. Outros sais contendo esse íon ou o íon arsenato, $\mathrm{AsO}_{4}^{3-}$, como os arsenatos de chumbo e de cálcio, também foram utilizados para este fim, em 1892 e 1907, respectivamente. Todos esses compostos atuam como venenos estomacais, matando os insetos que os ingerem. ${ }^{74}$ Compostos químicos tóxicos, como arsênio, mercúrio e chumbo, continuaram sendo amplamente utilizados como agrotóxicos durante as décadas de 30 e 40 e no início de 1950 . No século XIX, viu-se a introdução no meio ambiente de um composto natural, pyrethrum, que é derivado do chrysanthemums. ${ }^{75}$ Esse agrotóxico, feito a partir de flores secas das espécies $C$. cinerariifolium e $C$. coccineum, foi utilizado por séculos como inseticida. Embora os eventos e as datas relativas às propriedades inseticidas do pyrethrum sejam discrepantes na literatura, estudiosos sugerem que esta planta tenha sido usada como inseticida na Europa por mais de 160 anos, e por muito mais tempo na Pérsia. Essa planta foi obviamente conhecida bem antes que as suas qualidades como inseticida fossem identificadas. ${ }^{76}$ Entre 1940 e 1950, as indústrias químicas da América do Norte e da Europa Ocidental produziram grandes quantidades de agrotóxicos, especialmente inseticidas. Nessa época, os ingredientes ativos (i.a.) da maioria desses agrotóxicos eram organoclorados, muitos dos quais tinham em comum propriedades notáveis, como estabilidade com relação à decomposição ou à degradação ambiental; solubilidade baixa em água, a não ser que o oxigênio ou o nitrogênio se encontrem presentes nas moléculas; alta solubilidade em meios semelhantes aos hidrocarbonetos, como os tecidos gordurosos de organismos vivos e, toxicidade relativamente alta para insetos e seres humanos. ${ }^{77,78}$

Dentre os agrotóxicos organoclorados conhecidos, o composto denominado 1,1,1-tricloro-2,2-bis(4-clorofenil)etano, ou DDT, de fórmula molecular $\mathrm{C}_{14} \mathrm{H}_{9} \mathrm{Cl}_{5}$, foi um dos compostos mais importantes produzidos na história da humanidade, tanto por seus efeitos benéficos 
quanto pelos maléficos. Em virtude dessa importância, a história do DDT será mostrada detalhadamente no item a seguir.

\section{História do DDT}

Antes da descoberta do DDT existiam praticamente dois tipos de inseticidas: aqueles produzidos com o arsênio, cujas desvantagens eram a toxicidade elevada para humanos e a persistência no meio ambiente e, aqueles extraídos de plantas, que perdiam rapidamente a sua eficiência quando eram expostos a intempéries. Por isso, quando o DDT foi descoberto, foi tratado pela população como o primeiro inseticida ideal, pois não se conheciam os efeitos adversos, tanto à saúde humana como ao meio ambiente, advindos da sua utilização.

O DDT foi descoberto em 1939 por Paul Müller, ${ }^{79}$ um pesquisador da empresa suíça Geigy que descobriu a eficácia do DDT como inseticida e, por isso, recebeu o prêmio Nobel de Medicina e Fisiologia em 1948, em reconhecimento ao seu trabalho. Após essa data, o DDT transformou-se rapidamente no agrotóxico mais consumido mundialmente. Os produtos feitos com o DDT foram comercializados internamente na Suíça a partir de 1941. Como a Suíça manteve-se neutra durante a Segunda Guerra Mundial, o governo informou tanto aos Aliados quanto aos Países do Eixo sobre o descobrimento e os usos do DDT. Porém, somente os Aliados ocidentais perceberam a sua utilidade, em tempos de guerra, no combate às doenças infecciosas transmitidas por insetos em regiões de clima quente. Assim, esse composto foi aclamado "milagroso" por Sir Winston Churchill,,$^{80} \mathrm{em}$ 1945, por seu uso durante a Guerra. Uma vez finalizada a Segunda Guerra Mundial, o DDT começou a ser utilizado não apenas com propósitos de saúde pública em áreas de clima quente, mas também de forma extensiva e intensiva, em países desenvolvidos, para controlar as pragas dos insetos que atacavam as colheitas. Inicialmente, foi usado em árvores frutíferas e em lavouras de verduras e, posteriormente, nas plantações de algodão. Finalmente, de acordo com Himeidan et $a l .,{ }^{81}$ algumas populações de insetos tornaram-se resistentes à ação do DDT, diminuindo, então, a sua eficácia como inseticida. Esse fenômeno levou os agricultores a aplicarem quantidades cada vez maiores dessa substância, particularmente nos campos de algodão. O DDT foi muito efetivo contra os mosquitos transmissores da malária e da febre amarela, contra os piolhos que podem transmitir o tifo e contra as pragas de pulgas. ${ }^{82-88}$ A Organização Mundial da Saúde (World Health Organization) estimou que os programas de redução da malária, nos quais um dos componentes utilizados foi o DDT, salvaram a vida de mais de 5 milhões de pessoas. Evidências indicam que, dentre as pessoas salvas, a maioria eram crianças residentes, principalmente, em regiões com índice elevado de pobreza, incluindo vários países do continente africano. ${ }^{89,90}$

O DDT foi usado em excesso, particularmente na agricultura, na qual se consumiram $80 \%$ da sua produção. Como resultado, a concentração desse composto no meio ambiente elevou-se rapidamente e começou a afetar a capacidade reprodutiva das aves, que o incorporaram indiretamente em seus organismos. Entretanto, na década de 60, descobriu-se que, de fato, o DDT era o responsável por provocar danos à saúde de diversas espécies de pássaros, prejudicando a reprodução e oferecendo grandes riscos para a biodiversidade. Em 1962, em uma denúncia pública sobre os efeitos adversos do contato desse composto com aves, o DDT foi chamado de "elixir da morte", pela escritora Rachel Carson ${ }^{91}$ em seu livro Silent Spring (Primavera Silenciosa), ${ }^{92}$ devido ao papel desse inseticida na diminuição das populações de certos pássaros, como a águia-calva, cuja ingestão do produto em sua dieta foi muito elevada. No livro, Carson mostrou como o DDT penetrava na cadeia alimentar e se acumulava nos tecidos gordurosos dos animais, inclusive nos dos homens, com risco de causar câncer e alterações genéticas. ${ }^{92}$ Por exemplo, chegou a ser detectada a presença de DDT até no leite materno. ${ }^{93-101}$ A grande polêmica movida pelo instigante e provocativo livro é que ele não só expunha os perigos do DDT, mas questionava, de forma eloquente, a confiança "cega" da humanidade no progresso tecnológico. Dessa forma, o livro ajudou a abrir espaço para o movimento ambientalista que se seguiu. Rachel Carson foi uma das pessoas pioneiras da conscientização de que os homens e os animais estão em interação constante com o meio no qual vivem.

A partir da denúncia sobre os efeitos negativos do DDT, por meio de uma série de audiências legais promovidas por jurisconsultos e cientistas que trabalhavam para o Fundo de Defesa Ambiental (Environmental Defense Fund - EDF), nos Estados Unidos, o DDT teve o seu uso finalmente proibido ou severamente restrito na maioria dos estados. Em 1972, a Agência de Proteção Ambiental NorteAmericana (Environmental Protection Agency - EPA) proibiu todos os usos do DDT, exceto os indispensáveis para a saúde pública. ${ }^{102}$ Ações restritivas similares foram instituídas pela Suécia, em 1969, sendo, posteriormente, estabelecidas na maioria dos demais países desenvolvidos. Atualmente, o DDT é proibido em pelo menos 86 países. No entanto, ainda continua sendo usado em alguns países em desenvolvimento, no combate à malária e outras doenças tropicais. Porém, não obstante as ocorrências com o DDT, o desenvolvimento da síntese orgânica durante a Segunda Guerra Mundial e a consolidação do padrão tecnológico da agricultura, chamada moderna, tiveram importância fundamental no desenvolvimento da indústria mundial de agrotóxicos. A descoberta das propriedades inseticidas do organoclorado DDT, em 1939, é tida como um marco de transição nas técnicas de controle fitossanitário das culturas agrícolas. Segundo dados fornecidos pelo Departamento de Agricultura dos Estados Unidos (United States Department of Agriculture - USDA), ${ }^{103} \mathrm{em}$ geral, o uso de agrotóxicos dobrou desde a década de 50, e cerca de 2,5 milhões de t de agrotóxicos industriais são usados atualmente, por ano. No Brasil, a introdução de agrotóxicos organossintéticos teve o início em 1943, quando chegaram as primeiras amostras do inseticida DDT, que teve seu uso proibido efetivamente em 02 de setembro de 1985, por meio da Portaria n ${ }^{\text {. }} 329$, do Ministério da Agricultura, que proibiu em todo o território nacional a comercialização, distribuição e uso desse composto na agricultura. ${ }^{104}$

\section{Definição e classificação dos agrotóxicos}

Segundo o Decreto Federal Brasileiro no. 4.074, de 4 de janeiro de 2002, entendem-se por agrotóxicos: "produtos e agentes de processos físicos, químicos ou biológicos, destinados ao uso nos setores de produção, no armazenamento e no beneficiamento de produtos agrícolas, nas pastagens, na proteção de florestas, nativas ou plantadas e de outros ecossistemas e de ambientes urbanos, hídricos e industriais, cuja finalidade seja alterar a composição da flora ou da fauna, a fim de preservá-las da ação danosa de seres vivos considerados nocivos, bem como substâncias e produtos empregados como desfolhantes, dessecantes, estimuladores e inibidores do crescimento das plantas". ${ }^{70}$ De modo similar, a Agência de Proteção Ambiental Norte-Americana define o termo agrotóxico como sendo uma substância química ou mistura de substâncias utilizadas para prevenir, destruir, repelir ou mitigar qualquer praga, ou mesmo, para regular, desfolhar e dessecar plantas. ${ }^{105}$

Os agrotóxicos são definidos como substâncias que agem direta ou indiretamente em um organismo vivo, podendo matá-lo ou controlálo de alguma maneira, por exemplo, interferindo em seu processo reprodutivo. Em geral, a maioria desses compostos tem a propriedade comum de bloquear rápida e eficientemente um processo metabólico vital dos organismos para os quais são tóxicos. Por isto, são bastante empregados em diversos ramos de atividades e aplicações, em par- 
ticular, na agricultura.

Essas substâncias são classificadas em acaricidas, bactericidas, fungicidas, herbicidas, inseticidas, nematicidas, raticidas, vermífugos, entre outros, de acordo com as pragas que controlam. Os agrotóxicos também podem ser classificados em orgânicos: carbamatos (nitrogenados), clorados, fosforados e clorofosforados; inorgânicos: cujas composições químicas apresentam arsênio, tálio, bário, nitrogênio, fósforo, cádmio, ferro, selênio, chumbo, cobre, mercúrio e zinco e, botânicos: compostos de nicotina, piretrina, sabadina e rotenona (extraídas do timbó ou tingui - planta tóxica usada por índios brasileiros no preparo de arpões para pegar peixes)..$^{74}$

Dentre essas substâncias, destacam-se: 1) os inseticidas organoclorados, como os ciclodienos (por exemplo, aldrina, dieldrina, endrina, clordano, toxafeno, telodrina, isodrina, endossulfam, heptacloro e mirex); os diclorodifeniletanos e os seus derivados: por exemplo, DDT e metabólitos, 2,2-bis(p-clorofenil)-1,1-dicloroetileno (DDE) e 1,1-dicloro-2,2-bis( $p$-clorofenil)etano (DDD), bem como o metoxicloro; e os isômeros do hexaclorobenzeno, como os hexaclorocicloexanos $(\mathrm{HCH})$, sendo o lindano, ou $-\mathrm{HCH}$, o mais importante deles; 2) os inseticidas à base de organofosforados e carbamatos, como diclorvós, clorpirifós, parationa, diazinona, carbaril e carbofurano; 3 ) os fungicidas, como a vinclozolina (usada em frutas e verduras e cujos metabólitos apresentam atividades anti-androgênicas); 4) os herbicidas à base de triazinas, como atrazina e simazina, linurom, diurom e os seus metabólitos; e 5) os agrotóxicos organometálicos, como o tributilestanho (TBT), empregado como moluscicida, fungicida (como preservante de madeira), biocida e inseticida, bem como estabilizante de plásticos à base de policloreto de vinila (PVC) e ainda usado pela Marinha como algicida nas tintas aplicadas em embarcadouros, cascos de navios, recipientes para conserva de lagostas, redes de pesca, etc., com o objetivo de evitar incrustações e prevenir o acúmulo de organismos marinhos viscosos, como larvas de bálanos..$^{106-109}$

\section{O consumo de agrotóxicos no Brasil}

O padrão agrícola estabelecido no período pós-Segunda Guerra Mundial teve a sua base tecnológica assentada, principalmente, no uso de agrotóxicos e de agroquímicos (incluem os fertilizantes e os corretivos agrícolas), na mecanização do campo, em cultivares (variedade de qualquer gênero ou espécie vegetal, devendo ser passível de reprodução e descrita em publicação especializada disponível e acessível ao público) de alto potencial de rendimento e em técnicas de irrigação, visando a elevação dos índices de produtividade. A formação desse padrão nos países industrializados é resultado de processos contínuos de mudanças que a agricultura sofreu a partir da Revolução Industrial, quando as primeiras máquinas agrícolas vinham propor o desuso de ferramentas tradicionais. ${ }^{110}$ Nessa perspectiva, o padrão produtivo que se estabeleceu na agricultura brasileira seguiu uma visão modernizante neoclássica, defendida por Schultz, ${ }^{111}$ sendo chamada por alguns autores de modernização "parcial", "dolorosa" e "conservadora", pelo fato de alterar a base tecnológica produtiva, sem modificar a estrutura agrária vigente. ${ }^{112-114}$ Existe, portanto, uma estreita relação entre a agricultura moderna intensiva e a utilização de agrotóxicos.

A partir da década de 60, o modelo agrícola foi difundido para as regiões de países em desenvolvimento, num processo conhecido como Revolução Verde. Desde essa época, pesquisadores de vários países industrializados prometiam, através da invenção e da disseminação de novas sementes e práticas agrícolas, aumentar a produtividade na agricultura e resolver o problema da fome nos países em desenvolvimento. A introdução dessas práticas em países menos desenvolvidos provocou um aumento na produção agrícola de países não-industrializados. Nessa ocasião, países como o Brasil e a Índia foram alguns dos principais beneficiados. Juntamente com esses benefícios, alguns problemas começaram a surgir, sendo estes observados a partir do crescimento acelerado e desordenado do setor agrícola. ${ }^{115}$

A preocupação ambiental surgiu, então, a partir da década de 90 , quando a disseminação dessas práticas em todo o território nacional permitiu que o Brasil vivesse um surto de desenvolvimento agrícola, caracterizado pelo aumento da fronteira agrícola e pela propagação de culturas. Uma das maiores consequências desse crescimento foi o consumo elevado e descontrolado de agrotóxicos. Esses resultados puderam ser comprovados no final da década de 90 , mais especificamente no ano de 1998, quando pesquisas do Instituto Brasileiro de Geografia e Estatística (IBGE) indicaram que o consumo de agrotóxicos no Brasil correspondeu em cerca de 307 mil t de produtos comerciais (esses produtos correspondem aos produtos formulados, que contêm uma mistura de compostos em sua composição. Dentre esses compostos, está presente algum tipo de agrotóxico, denominado ingrediente ativo (i.a.). Normalmente o i.a. ou princípio ativo, composto químico destinado a debelar a praga, isoladamente não é apropriado para aplicação direta no ambiente. O agrotóxico necessita estar em formulação, forma conveniente para uso efetivo e seguro. A formulação permite mesclar o produto de grau analítico com elementos inertes, sólidos ou líquidos, de modo que tenha a concentração adequada, facilitando, assim, a sua manipulação, aplicação e transporte, bem como a dispersão, para um melhor desempenho sobre o vetor de doença ou praga a ser controlada, ${ }^{116}$ formulados com cerca de 250 i.a. diferentes. Expresso em quantidades de i.a., o consumo passou de 16 mil t, em 1964, para mais de 128 mil t, em 1998; enquanto a área ocupada com lavouras agrícolas no Brasil foi de 28 milhões de hectares (ha), em 1960, e de aproximadamente 50 milhões de ha, em 1998. Notem que, a área com culturas agrícolas aumentou aproximadamente $78 \%$, enquanto que, no mesmo período, o aumento no consumo de agrotóxicos foi cerca de $700 \%$. O consumo desses produtos difere nas várias regiões do país, nas quais se misturam as atividades agrícolas intensivas às tradicionais, sendo que essas últimas não incorporaram o uso intensivo desses produtos químicos. ${ }^{117-119}$

Em 1998, período marcado por grandes avanços na produção agrícola nacional, os agrotóxicos foram mais usados nas regiões Sudeste, Sul e Centro-Oeste, com consumo, respectivamente, de 38,9; 31,2 e $22,8 \%$ dos agrotóxicos utilizados no Brasil. Nas demais regiões, essas porcentagens foram menores. O consumo de agrotóxicos na região Norte foi, comparativamente, muito pequeno $(1,3 \%)$, enquanto na região Nordeste $(5,8 \%)$ o uso foi principalmente concentrado nas áreas de agricultura irrigada. Na região Centro-Oeste o consumo de agrotóxicos aumentou consideravelmente durante as décadas de 70 e 80, devido principalmente à ocupação dos Cerrados, sendo que o mesmo continua crescendo pelo aumento da área plantada naquela região, em especial, com o cultivo da soja e do algodão. Destacam-se, quanto à utilização de agrotóxicos, os estados de São Paulo $(25,2 \%)$, Paraná (16,2\%), Minas Gerais (12,1\%), Rio Grande do Sul (12,0\%), Mato Grosso (9,4\%), Goiás (7,6\%) e Mato Grosso do Sul $(5,5 \%)$. Quanto ao consumo de agrotóxicos por unidade de área cultivada, a média geral passou de 0,8 kg de i.a. ha-1, em 1970, para 7,0 kg de i.a. ha ${ }^{-1}$, em 1998. Em termos de quantidade total de i.a., as culturas agrícolas brasileiras nas quais mais se utilizaram agrotóxicos foram: soja, milho, citros e cana-de-açúcar. ${ }^{117-119}$

Sabe-se que a produção agrícola moderna na maioria dos países depende grandemente do uso de agrotóxicos. Como mostra o último relatório de Indicadores de Desenvolvimento Sustentável divulgado pelo IBGE, em 2004, o uso de agrotóxicos no Brasil foi de, aproximadamente, $2,8 \mathrm{~kg} \mathrm{ha}^{-1}$. Segundo esse relatório, em comparação aos anos anteriores, embora o uso de agrotóxicos revele tendência de estabilidade, verificou-se que os agricultores vêm optando por produtos 
menos tóxicos. Dentre os agrotóxicos utilizados, os herbicidas são os mais consumidos no Brasil, seguidos dos inseticidas, fungicidas e acaricidas. A utilização dos herbicidas representa mais de $50 \%$ do total de agrotóxicos e tem sido associada ao modelo de plantio direto (sem revolver a terra), que favorece o crescimento de ervas daninhas na área de plantio. Por exemplo, em 2001, para 50,7 milhões de ha de área plantada, o Brasil utilizou 158,7 mil t de agrotóxicos, das quais 91,8 mil t foram de herbicidas. ${ }^{120}$

Outros agrotóxicos bastante utilizados são os fungicidas, que representam cerca de $20 \%$ do total aplicado. Os fungicidas têm sido largamente empregados para controlar vários fungos patogênicos existentes em frutas e verduras durante os períodos de pré-colheita e, também, de pós-colheita. Em consequência, resíduos de fungicidas têm sido frequentemente encontrados nesses alimentos. ${ }^{121-125}$

Segundo dados do Sindicato Nacional da Indústria de Produtos para Defesa Agrícola (SINDAG), em 2005, o Brasil consumiu mais de 365 mil t de agrotóxicos, movimentando mais de 4 bilhões de dólares. ${ }^{126}$ Números estes, que colocam o Brasil em quarto lugar no ranking mundial do consumo de agrotóxicos. O lucro elevado justifica, em parte, a defesa do uso desses produtos no mercado agrícola. Além disso, os agrotóxicos são utilizados em menores proporções, em residências, como os eliminadores de ervas daninhas, para o gramado ou jardim; os controladores de algas, para o tratamento de águas de piscinas; os talcos antipulgas, para a proteção de animais de estimação e, os aerossóis, para matar insetos. ${ }^{74}$

Assim como no Brasil, as classes de agrotóxicos mais utilizados em todo o mundo são as dos inseticidas, herbicidas e fungicidas. Em conjunto, essas três categorias representam a grande quantidade de agrotóxicos que se estima em torno de bilhões de quilogramas, usados anualmente, principalmente na agricultura. As capacidades atuais, principalmente relacionadas aos países desenvolvidos, de produzir e colher grandes quantidades de alimentos em áreas relativamente pequenas, com a participação reduzida de trabalho humano, têm sido possíveis especialmente com o uso de agrotóxicos.

\section{A problemática ambiental e de saúde pública relacionada aos efeitos nocivos do uso de agrotóxicos}

Praticamente, desde a primeira utilização, os agrotóxicos sintéticos constituem um problema ambiental considerável, principalmente, devido ao impacto potencial à saúde humana em virtude da ingestão de alimentos contaminados com esses produtos químicos. Pesquisas mostram que cerca da metade dos alimentos consumidos nos Estados Unidos contém níveis mensuráveis de, no mínimo, um tipo de agrotóxico. Não obstante, em 1993, uma publicação da Academia Nacional de Ciências dos Estados Unidos (National Academy of Sciences - NAS) destacou que a regulamentação dos agrotóxicos até a data dessa publicação não havia dado atenção suficiente à proteção da saúde humana, especialmente à dos bebês e das crianças, cujo crescimento e desenvolvimento se apresentam ameaçados quando postos em contato com essas substâncias. ${ }^{127}$

Muitos estudos foram realizados com agricultores com o objetivo determinar os efeitos nocivos à saúde ocupacional resultantes do contato com os agrotóxicos. ${ }^{122}$ No entanto, as pesquisas indicaram que a exposição aos agrotóxicos está associada, em curto e em longo prazo, com vários sintomas de saúde, como dificuldades respiratórias, problemas de memória e de pele, ${ }^{124,128}$ câncer, ${ }^{129}$ depressão, ${ }^{130}$ entre outros. No meio ambiente, o uso de agrotóxicos destinados ao controle de pragas na agricultura deve ser moderado e aplicado com alguns cuidados, caso contrário, pode causar a contaminação e até a desertificação do solo. $\mathrm{O}$ uso intenso de agrotóxicos pode causar a degradação dos recursos naturais, em alguns casos de forma irreversível, levando à ocorrência de desequilíbrios biológicos e ecológicos, entre eles a contaminação de lençóis freáticos e aquíferos. ${ }^{131-135}$
Para enfatizar a extensão desse problema ambiental, as pesquisas realizadas pelo Serviço Geológico dos Estados Unidos (United States Geological Survey - USGS $)^{136}$ mostram que os agrotóxicos têm sido encontrados frequentemente em lagos, rios e córregos. É importante mencionar que tal situação também se repete em outros países, como o Brasil. Geralmente, dentre os diversos compartimentos ambientais, os ambientes aquáticos são bastante afetados pelo uso de agrotóxicos. Para os anfíbios, por exemplo, esses compostos são comumente letais, mesmo em concentrações da ordem de micrograma por litro. ${ }^{137}$

Portanto, os agrotóxicos além de cumprirem o papel de proteger as culturas agrícolas das pragas, doenças e plantas daninhas, também podem oferecer riscos à saúde humana e ao meio ambiente. Os usos frequentes de agrotóxicos, muitas vezes incorretos, favorecem os riscos de contaminação de diversos compartimentos ambientais, como a contaminação de solos agrícolas, de águas superficiais e subterrâneas e de alimentos, podendo, em episódios mais graves, inviabilizar o consumo destes. Isso pode apresentar, consequentemente, riscos de efeitos negativos em organismos terrestres e aquáticos, como intoxicação pelo consumo de água e de alimentos contaminados, além da intoxicação ocupacional de trabalhadores e produtores rurais. $\mathrm{Na}$ Figura 1 são apresentados, esquematicamente, os processos principais que atuam na movimentação e na degradação de agrotóxicos na natureza, ilustrando os meios mais prováveis onde esses compostos podem ser encontrados. ${ }^{138}$

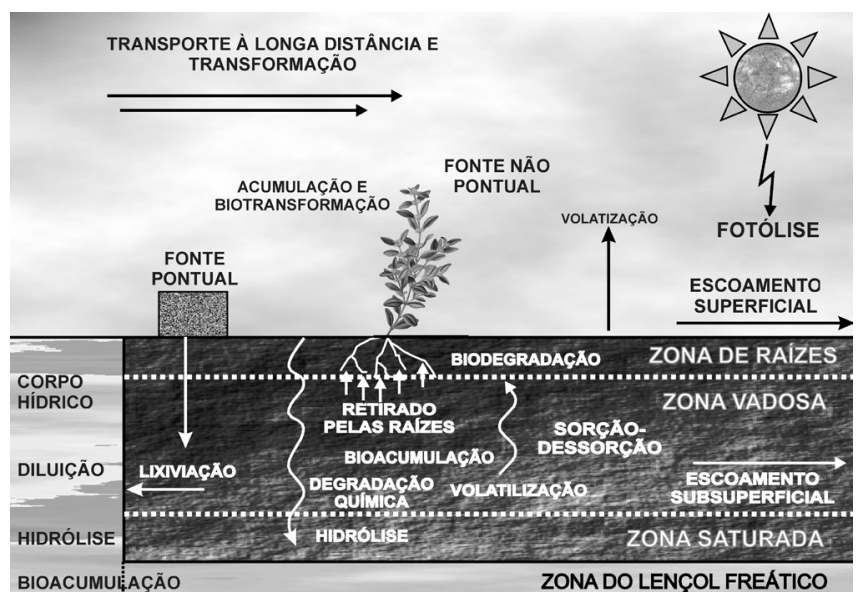

Figura 1. Principais rotas de transporte e degradação de agrotóxicos no ambiente. Adaptada da ref. 138

Em vista dos problemas mencionados, as medidas mais importantes para minimizar o risco potencial da contaminação por agrotóxicos em humanos são, não somente monitorá-los nos produtos agrícolas e em frutas e verduras, ${ }^{37,139}$ mas também propor e empregar formas alternativas que visem a redução desses compostos durante, principalmente, as etapas de plantio de uma determinada cultura. De modo geral, quando os agrotóxicos são aplicados seguindo as Boas Práticas Agrícolas (BPA), ${ }^{140}$ os LMR não são excedidos, porém, a má utilização desses compostos é que se torna preocupante, podendo deixar quantidades significativas de resíduos tanto em alimentos ${ }^{141}$ quanto e em compartimentos ambientais. ${ }^{142}$

Entretanto, o monitoramento de agrotóxicos no meio ambiente é uma ferramenta de suma importância para a caracterização e o gerenciamento dos riscos ambientais decorrentes do uso desses produtos em condições reais. Além disso, conforme preconizado pelo Decreto Federal Brasileiro n ${ }^{\mathrm{o}} 4.074$ de 2002, o monitoramento desses compostos também pode fazer parte da avaliação em processo de registro de novos produtos, ou ainda, da reavaliação de produtos em uso. ${ }^{70}$ 


\section{Persistência dos agrotóxicos no meio ambiente}

Durante e após a Segunda Guerra Mundial foram desenvolvidos muitos inseticidas orgânicos que substituíram, em grande proporção, as substâncias inorgânicas e as organometálicas. Em geral, a maioria dos agrotóxicos orgânicos e organometálicos é bastante tóxica para os seres humanos e outros mamíferos, especialmente, nos níveis de dosagens requeridos para torná-los efetivos nas aplicações em campo. Os agrotóxicos orgânicos foram inicialmente projetados para serem biodegradáveis, embora se saiba que isto não acontece em muitos casos. Além disso, metais e semimetais (metalóides) tóxicos, como o arsênio, usado comumente em alguns agrotóxicos, não são biodegradáveis. Uma vez lançados no ambiente tendem a permanecer indefinidamente em plantas, águas, solos ou sedimentos, podendo integrar-se à cadeia alimentar, caso eles sejam liberados nesses locais. ${ }^{143-146}$

Os maiores problemas ligados à persistência de agrotóxicos no meio ambiente estão relacionados à utilização dos agrotóxicos organoclorados. Nesses compostos, a ligação carbono-cloro, presente na estrutura molecular, é difícil de ser rompida e o cloro pode reduzir a reatividade de outras ligações das moléculas orgânicas. Em muitas aplicações a falta de reatividade química é considerada como sendo uma vantagem importante, porém, também significa que, uma vez que os organoclorados tenham sido lançados no meio ambiente, eles se degradam muito lentamente, tendendo, portanto, a se acumularem. Como exemplo, pode-se citar o caso do composto organoclorado hexaclorobenzeno ( $\mathrm{HCB}), \mathrm{C}_{6} \mathrm{Cl}_{6}$, que foi utilizado durante várias décadas após a Segunda Guerra Mundial como fungicida de uso agrícola nas colheitas de cereais. Devido a sua estabilidade elevada, é considerado como sendo extremamente persistente no meio ambiente. O HCB pode ser gerado como um subproduto indesejável na síntese de outros compostos organoclorados, como o percloroetileno (PCE), o tricloroetileno (TCE), o tetracloreto de carbono e o pentaclorofenol. Essa substância também pode ser formada como subproduto da combustão incompleta, ocorrida durante a incineração de materiais contendo cloro, em processos como a incineração de lixo urbano e a queima de carvão para a produção de cimento. Em consequência, o HCB permanece como um agente causador de contaminação ambiental amplamente difundida nos dias atuais e é um composto considerado problemático perante as agências ambientais, pois pode causar câncer de fígado em roedores de laboratório e, deste modo, também se suspeita que o mesmo seja um agente carcinogênico para os humanos. ${ }^{74}$ De fato, em muitos países, vários seres vivos sofreram ou ainda sofrem pela contaminação por esses produtos químicos. Por isso, muitos esforços dos órgãos governamentais e de grupos ambientais são realizados no sentido de documentar essa contaminação e regulamentar o uso de compostos organoclorados, impedindo, se possível, que as suas concentrações atinjam níveis perigosos, particularmente, sobre a dieta alimentar humana. ${ }^{147-150}$

Em corpos aquáticos, como rios e lagos, os organoclorados têm uma probabilidade muito maior de estarem ligados à superfície do material orgânico particulado em suspensão na água e aos sedimentos nas regiões mais profundas, que de estarem dissolvidos na própria água. A partir dessas fontes de contaminação, os agrotóxicos se introduzem nos organismos vivos, como nos peixes. Por estas razões, a concentração desses compostos em peixes é, com frequência, milhares ou milhões de vezes maior que a concentração dissolvida em água. ${ }^{151-153}$ A poluição dos ambientes aquáticos não é meramente uma questão da concentração do poluente que se encontra somente no estado dissolvido, pois nota-se que os pequenos valores de solubilidade dos organoclorados em água podem ser enganosos, haja vista que esses compostos estão localizados, em maiores concentrações, em fontes diferentes do meio aquoso. Como a maioria dos compostos organoclorados, no meio ambiente o HCB é mais solúvel em meios orgânicos naturais que em águas. Devido a essa característica, a concentração de organoclorados frequentemente tem atingido níveis preocupantes em muitas espécies. ${ }^{154}$ Diante disso, como consequência, o uso de muitos inseticidas organoclorados foi banido.

Desde 22 de maio de 2001, pessoas representantes de 151 países que fazem parte da Convenção de Estocolmo buscam desenvolver medidas efetivas para banir os compostos, denominados de poluentes orgânicos persistentes (POP). ${ }^{155}$ Os 12 compostos de uso proibido pela Convenção incluem aldrina, clordano, DDT, dieldrina, endrina, heptacloro, hexaclorobenzeno, mirex, toxafeno, bifenilas policloradas (PCB), dioxinas e furanos. Todas essas substâncias são comprovadamente tóxicas e podem causar distúrbios de saúde em humanos. Dentre os compostos listados acima, apenas os DDT e as PCB terão uma eliminação gradual. No caso do primeiro, o uso é permitido apenas para o combate aos vetores transmissores da malária. No Brasil, o texto da Convenção de Estocolmo sobre os poluentes orgânicos persistentes, adotado naquela cidade, foi aprovado pelo Senado Federal, através do Decreto Legislativo n ${ }^{\text {o. }}$ 204, em 7 de maio de 2004..$^{156}$

Ressalta-se, porém, que a lista das substâncias mais tóxicas não foi feita apenas por causa do impacto que exercem sobre a saúde humana. Nesse caso, no que tange à toxicidade e à persistência desses compostos, além da questão ambiental ser considerada, nota-se que a maioria dessas substâncias permanece durante muito tempo no ambiente sem ser degradada. Por conseguinte, uma das principais fontes de exposição humana a esses compostos está localizada em alimentos, principalmente durante o consumo de peixes e derivados, de animais com altos teores de gorduras, ${ }^{157}$ além de frutas e verduras, conforme foi relatado em trabalhos publicados por pesquisadores como Wang et al. ${ }^{36}$ e Hill e Reynolds. ${ }^{158}$

\section{Toxicologia dos agrotóxicos}

A toxicologia é o estudo dos efeitos nocivos de substâncias sobre os seres vivos. As substâncias de interesse incluem tanto os produtos químicos sintéticos quanto aqueles naturalmente presentes no ambiente. Com relação ao estudo toxicológico dos agrotóxicos, a priori, devem ser analisadas as consequências ambientais associadas ao uso desses produtos químicos, com ênfase nas substâncias cuja toxicidade chega a afetar a saúde humana, especialmente no que diz respeito ao câncer e aos defeitos congênitos, bem como o bem-estar de organismos inferiores. Em geral, na toxicologia os efeitos são determinados pela injeção ou pela administração oral da substância em animais, observando-se como a saúde dos mesmos pode ser afetada. ${ }^{159}$

Um agrotóxico fortemente complexado pode não estar biodisponível e, consequentemente, não apresentar toxicidade a um determinado organismo. Dessa forma, nem sempre a concentração total do composto em questão reflete a toxicidade real, por isso, é de suma importância estudar a biodisponibilidade do composto alvo, considerando cada fator individual, como as vias de exposição humana (ocular, respiratória, dérmica e oral), inclusive as condições físicas, químicas e biológicas do local onde estão presentes os agrotóxicos. Os métodos diferentes disponíveis para avaliação dos riscos são similares, no que diz respeito à necessidade de se obter dados sobre a exposição da população afetada e sobre os efeitos dos contaminantes nessa população ou em outros organismos indicadores. ${ }^{160,161}$

No Brasil, a toxicidade aguda dos agrotóxicos é expressa em termos de valor da dose letal 50\% (Lethal Dose $50 \%$ ou $\mathrm{LD}_{50}$ ), que é a dose de uma substância química que provoca a morte de, pelo menos, $50 \%$ das espécies estudadas (geralmente, ratos ou camundongos), quando administrada pela mesma via, por exemplo, oral. $\mathrm{A} \mathrm{LD}_{50}$ é representada pela relação mássica, ou seja, miligramas do produto tóxico por quilograma de massa viva (m.v.). Assim, para 
fins de prescrição das medidas de segurança contra os riscos à saúde humana, os produtos comerciais devem ser enquadrados em função da $\mathrm{LD}_{50}$, inerente a cada substância. Nesse contexto, o Ministério da Saúde divide os agrotóxicos em quatro classes toxicológicas: Classe I (compostos extremamente tóxicos, $\mathrm{LD}_{50} \leq 5 \mathrm{mg} \mathrm{kg}^{-1}$ de m.v.), Classe II (altamente tóxicos, $5<\mathrm{LD}_{50} \leq 50 \mathrm{mg} \mathrm{kg}^{-1}$ de m.v.), Classe III (medianamente tóxicos, $50<\mathrm{LD}_{50} \leq 500 \mathrm{mg} \mathrm{kg}^{-1}$ de m.v.) e Classe IV (pouco ou muito pouco tóxicos, $\mathrm{LD}_{50}>5000 \mathrm{mg} \mathrm{kg}^{-1}$ de m.v.). ${ }^{162}$

Os dados toxicológicos relacionados à nocividade de uma determinada substância para um organismo são coletados mais facilmente determinando-se a sua toxicidade aguda, que é o início rápido dos sintomas (incluindo a morte no limite extremo) que se seguem à absorção de uma dose conhecida da substância. Embora a toxicidade aguda, exposição acentuada a uma substância, seja de grande interesse quando ocorre acidentalmente, na toxicologia ambiental, a maior preocupação se dá mediante as exposições que acontecem em longo prazo, às doses individuais relativamente baixas de uma determinada substância tóxica presente no meio ambiente, que é denominada toxicidade crônica. De modo geral, quaisquer efeitos como, por exemplo, câncer ou defeitos congênitos decorrentes dessas exposições contínuas são de longa duração e, portanto, classificados como crônicos. ${ }^{159,163,164}$

A análise dos dados toxicológicos evidencia que os problemas enfrentados atualmente, causados pelo uso de agrotóxicos, não são exclusividade do Brasil, destacando, também, que mesmo nos países considerados mais desenvolvidos esses problemas ocorrem pelas mesmas razões discutidas anteriormente. Nesse contexto, um dos principais programas ambientais dos Estados Unidos, conhecido como Superfund, foi instituído em 1980 pelo Decreto denominado Comprehensive Environmental Response, Compensation, and Liability Act (CERCLA). O objetivo principal do CERCLA é remediar as chamadas áreas órfãs contaminadas, inclusive por agrotóxicos, cujos riscos à saúde da população ou ao meio ambiente são reconhecidamente elevados e onde não existe um responsável identificado, ou o responsável identificado não possua condições financeiras para arcar com os custos de investigação de passivo e de remediação. $\mathrm{O}$ programa possui um cadastro das áreas contaminadas denominado Comprehensive Environmental Response, Compensation and Liability System (CERCLIS) e uma lista das áreas consideradas prioritárias para remediação, denominada National Priorities List (NPL). ${ }^{165}$

Com base nos regulamentos estipulados pelo Decreto CERCLA, a Agência para o Registro de Substâncias Tóxicas e de Doenças (Agency for Toxic Substances and Disease Registry - ATSDR) em conjunto com a EPA são responsáveis pelo preparo e atualização de uma lista de compostos químicos considerados de grande periculosidade ao meio ambiente. Nesta lista, conhecida como Lista Prioritária de Substâncias Perigosas (Priority List of Hazardous Substances - PLHS) do CERCLA, os compostos são dispostos em ordem decrescente de prioridade adotando os seguintes critérios de avaliação: frequência de ocorrência das substâncias comumente encontradas nas áreas relacionadas na NPL; toxicidade do composto alvo para a saúde humana e, risco potencial à exposição humana. Considerando estes três critérios, cada condição é, então, valorada e, em seguida, os valores obtidos são tratados como algoritmos, resultando no ranking de substâncias perigosas. ${ }^{165}$

Devido à importância da PLHS, que trata cada composto de modo individual e ainda considera as características intrínsecas de cada substância, incluindo não somente a toxicidade, mas também a biodisponibilidade e as diferentes vias de exposição humana, os dados dessa lista são utilizados como referência em estabelecimentos governamentais de diversos países do mundo, dentre eles os órgãos de fiscalização ambiental, como a CETESB. Por isto, recomenda-se aqui que essa lista seja também utilizada em trabalhos que envolvam a determinação de resíduos de agrotóxicos em quaisquer amostras. Nesse caso, a consulta prévia da lista irá auxiliar, dentre outros fatores, na escolha dos principais tipos de agrotóxicos a serem monitorados na matriz em estudo. É claro que a utilização da PLHS deve ser feita sempre que necessário, sendo que os dados contidos na Lista podem ser extrapolados para quaisquer estudos de áreas contaminadas e trabalhos relacionados, por exemplo, à remediação ambiental.

\section{Legislação ambiental}

No que tange à legislação ambiental brasileira, a CETESB, em conjunto com o Ministério da Saúde, definiu os limites máximos permitidos para alguns agrotóxicos presentes em compartimentos ambientais, como solos e águas subterrâneas. Por outro lado, a ANVISA dispõe sobre o uso de agrotóxicos (durante o pré-plantio, o manejo e o pós-plantio) em diversos cultivares e estabelece os LMR desses compostos em alimentos. ${ }^{125}$

Para a proteção da qualidade de solos e águas subterrâneas, órgãos de legislação e de controle ambiental de cada país adotam diferentes cenários de contaminação, por exemplo, a Holanda considera como fator majoritário a multifuncionalidade de uso do solo; a Alemanha, parques infantis, parques recreativos, áreas residenciais, industriais e comerciais; a Inglaterra, áreas residenciais e parques públicos; o Canadá, áreas agrícolas, residenciais e industriais; e os Estados Unidos, áreas residenciais e industriais. No Brasil, mais especificamente no estado de São Paulo, a CETESB estabeleceu valores orientadores (valores de referência de qualidade, de alerta e de intervenção) para solos e águas subterrâneas. Esses valores são descritos apenas para alguns tipos de agrotóxicos (aldrina e dieldrina, DDT, endrina, lindano e HCB) e foram definidos com base em dados nacionais e em avaliação de risco à saúde humana, cujas respostas foram obtidas a partir do gerenciamento da qualidade dos solos e das águas subterrâneas. Os valores orientadores foram estabelecidos para serem utilizados como um instrumento ágil e de fácil aplicação no suporte às decisões para as ações de prevenção e controle da poluição dos solos e das águas subterrâneas, pelos diferentes usuários, de maneira padronizada. ${ }^{166-168}$

A ANVISA, através da Resolução da Diretoria Colegiada (RDC) $\mathrm{n}^{\text {o. }} 216$, de 15 de dezembro de $2006,{ }^{169}$ considerando a necessidade de atualizar a apresentação de relatórios de estudos de resíduos de agrotóxicos e afins em conformidade com as normas do Codex Alimentarius, da Organização das Nações Unidas para a Alimentação e a Agricultura (Food and Agriculture Organization of the United Nations - FAO), da União Internacional de Química Pura e Aplicada (International Union of Pure and Applied Chemistry - IUPAC) e da Organização para a Cooperação e o Desenvolvimento Econômico (Organisation for Economic Co-operation and Development - OECD), adota e define LMR de agrotóxicos em produtos de origem vegetal e em cogumelos in natura destinados ao consumo humano e/ou animal, visando a garantia de acesso da população aos alimentos seguros, no tocante aos resíduos químicos. ${ }^{169} \mathrm{Em}$ função do expressivo número de agrotóxicos regulamentados pela ANVISA (mais de 300 princípios ativos em mais de 2.000 formulações comerciais diferentes), os LMR estabelecidos para cada composto não serão aqui apresentados, porém, podem ser acessados a qualquer momento no site oficial da ANVISA, http://www.anvisa.gov.br/.

Com relação à legislação ambiental de agrotóxicos é importante ter conhecimento de dois aspectos: como os órgãos de fiscalização e legislação ambiental definem o LMR aceitável para a ingestão por seres humanos e, determinar porque alguns agrotóxicos estão proibidos para determinadas culturas. As doses de agrotóxicos usadas atualmente na agricultura convencional foram elaboradas a partir da ingestão diária aceitável (IDA). Segundo esse paradigma, o organismo 
humano pode ingerir, inalar ou absorver certa quantidade diária, sem que isso tenha consequência para a sua saúde. Em síntese, a IDA deriva de um outro relevante conceito, a toxicidade aguda. Considerando essas informações, deve-se ressaltar que, normalmente, a maioria desses compostos se potencializa mutuamente, mas, salienta-se que a IDA não contempla essa interação. Outra informação importante é que, como é observado na prática, o efeito sinérgico (quando o efeito dos compostos aplicados associados é maior que a soma dos efeitos isolados) obtido com a mistura de agrotóxicos não está preconizado na "Lei de Agrotóxicos" e, ao contrário, deveria sim ser considerado, haja vista a relevância desse conceito e, principalmente, a relação direta com a saúde pública da população.

\section{PRODUÇÃO AGRÍCOLA DE ALIMENTOS NO BRASIL}

No Brasil, o Ministério do Planejamento, Orçamento e Gestão, através do IBGE, desde 1972, realiza pesquisas mensais sobre a previsão e o acompanhamento das safras agrícolas, apresentando tabelas com informações das estimativas de produção, do rendimento médio e das áreas plantadas e colhidas, tendo como unidade de coleta os municípios. Incluem, ainda, comentários sobre as perspectivas de desempenho das safras. Dentre as informações relevantes, constatase que, atualmente, o Brasil é o terceiro maior produtor mundial de frutas, perdendo apenas para China e Índia, liderando o mercado e atuando como o principal exportador mundial.

Em abril de 2007, foi feito um levantamento sistemático da produção agrícola, sendo que os resultados foram divulgados no relatório de indicadores do IBGE. ${ }^{170}$ Neste levantamento foram investigadas as culturas dos seguintes produtos: algodão (caroço de algodão), amendoim, arroz, aveia, centeio, cevada, feijão, girassol, mamona, milho, soja, sorgo, trigo e triticale (um cereal resultante da hibridação, ou seja, cruzamento artificial de duas espécies distintas, o trigo e o centeio. A cultura vem sendo pesquisada no Brasil desde 1969 e o primeiro cultivar foi lançada em 1985). Com base nesse relatório do IBGE, a área plantada e a produção de cereais, leguminosas e oleaginosas para as principais regiões do Brasil estão mostradas na Tabela $1 .{ }^{171}$

A Tabela 1 mostra que o Brasil possui atualmente mais de 45 milhões de ha de áreas de cultivo agrícola, sendo que a maior parte dessas áreas está localizada na região Sul, com 37,6\% das áreas plantadas. Em seguida, destacam-se as regiões Centro-Oeste, Nordeste, Sudeste e, por último, a Região Norte com, respectivamente, 30,$2 ; 18,0 ; 10,6$ e 3,6\% do total de áreas. Considerando as culturas plantadas nessas áreas, para a safra agrícola de 2007 foi prevista uma produção de mais de 132 milhões de t de alimentos, incluindo cereais, leguminosas e oleaginosas. A análise dos dados da Tabela 1 também revela que apesar do Nordeste apresentar um maior número de áreas plantadas em comparação à região Sudeste, esta contribui com $12 \%$ da produção nacional, cuja produção de alimentos é superior àquela da região Nordeste (participação de $8,6 \%$ do total produzido no Brasil). ${ }^{171}$

\section{MAÇÃS}

A maçã é um dos tipos de frutas mais cultivadas no mundo, com mais de 7.500 espécies e variedades. É cultivada em todos os continentes, com maior concentração na Ásia, tendo 60\% do total da área cultivada. Fruta típica das regiões temperadas, e tão antiga quanto a humanidade, é uma das frutas mais completas sob o ponto de vista nutricional. Possui componentes antioxidantes, vitaminas, niacina e sais minerais, como fósforo e ferro. Pesquisas comprovam que o elevado valor nutritivo de maçãs está associado, principalmente, à presença de compostos fenólicos, como ácido clorogênico, procianidina $\mathrm{B}_{2}$, quercetina e vitaminas $\mathrm{B}_{1}, \mathrm{~B}_{2}$ e C. ${ }^{172}$ As vitaminas do Complexo B ajudam a regular o sistema nervoso e o crescimento, evitam problemas de pele, do aparelho digestivo e a queda dos cabelos. O fósforo previne a fadiga mental, retarda o envelhecimento precoce, além de contribuir para a formação dos ossos e dentes. O ferro é importante na formação do sangue. A quercetina ajuda a evitar a formação dos coágulos sanguíneos capazes de provocar acidente vascular cerebral (AVC) e é um oxidante que combate o colesterol. $A$ vitamina $C$ ajuda a combater radicais livres, que são os principais responsáveis pelas causas de várias doenças, como o câncer e as doenças coronarianass. ${ }^{173}$

A maçã é recomendada para pessoas com problemas no intestino, obesidade, reumatismo, gota, diabetes, enfermidades da pele e do sistema nervoso. A sua casca seca é empregada como chá para purificar o sangue e também atua como diurético. Para o melhor aproveitamento das vitaminas presentes nessa fruta, o ideal é consumíla naturalmente com casca, pois é junto dela que está localizada a maior parte das vitaminas e dos sais minerais. Em geral, as maçãs são consumidas frescas ou na forma de produtos processados, como sucos, geléias, doces, sidras, vinagres, chá, polpas desidratadas e em alimentos para bebês.

Recomenda-se o plantio nos meses de junho a setembro. Apesar das maçãs serem vendidas durante o ano todo no Brasil, o período de safra é somente entre janeiro e abril. Após esse período, praticamente a maioria das maçãs comercializadas no mercado brasileiro é importada de outros países, como a China.

\section{Produção nacional de maçãs}

O cultivo comercial da macieira no Brasil é relativamente recente e se estabeleceu através de grandes empresas atraídas por incentivos de políticas públicas. Em 1969, o Governo Federal incluiu a macieira na Lei de Incentivos Fiscais para Reflorestamento, ${ }^{174}$ permitindo que até $50 \%$ do valor do imposto de renda de pessoa jurídica fosse aplicado em reflorestamentos, com o objetivo de diminuir a dependência de outros países para o consumo da fruta. A criação dessa Lei permitiu o surgimento dos primeiros pomares comerciais em Santa Catarina (Fraiburgo e municípios vizinhos), Paraná e Rio Grande do Sul. A partir dessa data, o cultivo da macieira despertou o interesse de muitos produtores agrícolas e, com isso, grandes empresas instalaram pomares e montaram toda a infra-estrutura de câmaras frigoríficas, transporte a frio e de comercialização. ${ }^{175}$

Segundo informações do IBGE, em 1974 a produção nacional de maçãs atingia apenas 1,53 mil t. Em 1990, esse valor subiu para 351 mil t da fruta. Entre 2000 e 2001 (os dados de 2001 estão sublinhados),

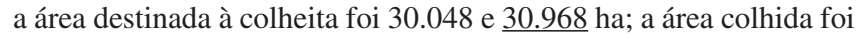
30.043 e $\underline{30.938}$ ha; a quantidade produzida foi 5.766 .347 e $\underline{716.030}$ mil frutos; o rendimento médio foi 191.936 e 23.144 frutos ha ${ }^{-1} \mathrm{e}, \mathrm{o}$ valor de produção de maçãs no Brasil foi 419.504 e $\underline{355.660}$ mil reais. Na safra de 2004, ${ }^{176}$ um ano considerado atípico pelos agricultores, a produção brasileira de maçãs atingiu valores recordes, com aproximadamente 973 mil t e rendimento médio de $29,63 \mathrm{t} \mathrm{ha}^{-1}$. Como mostra a Figura 2, em 2005 foram produzidas 843.919 t de maçãs, sendo 504.994 t provenientes de Santa Catarina, 296.775 t do Rio Grande do Sul, 40.275 do Paraná e 1.875 de São Paulo. ${ }^{177}$

Recentemente, o IBGE divulgou o último relatório de 2007, referente ao levantamento sistemático da produção agrícola de maçãs para a safra atual. A Tabela 2 mostra os resultados dessa pesquisa, na qual foi feito um estudo comparativo entre os valores obtidos na safra de 2006 e a projeção para a safra de 2007. Consideraram-se diferentes parâmetros, como a área total plantada e a área a ser colhida, a produção e o rendimento médio das lavouras de maçãs do Brasil. ${ }^{178}$

Os dados apresentados na Tabela 2 mostram que a produção de 
Tabela 1. Relação da área plantada e da produção de cereais, leguminosas e oleaginosas nas principais regiões do Brasil - safra de 2007. Adaptada da ref. 171

\begin{tabular}{|c|c|c|c|c|}
\hline Unidades da Federação & Área (ha) & $\begin{array}{c}\text { Participação da área do } \\
\text { Brasil (\%) }\end{array}$ & Produção (t) & $\begin{array}{c}\text { Participação da produção } \\
\text { do Brasil (\%) }\end{array}$ \\
\hline Brasil & 45600037 & 100,0 & 132250033 & 100,0 \\
\hline Norte & 1642449 & 3,6 & 3422240 & 2,6 \\
\hline Rondônia & 344326 & 0,8 & 712732 & 0,5 \\
\hline Acre & 74049 & 0,2 & 93189 & 0,1 \\
\hline Amazonas & 40535 & 0,1 & 71547 & 0,1 \\
\hline Roraima & 34987 & 0,1 & 135908 & 0,1 \\
\hline Pará & 642981 & 1,4 & 1271162 & 1,0 \\
\hline Amapá & 6420 & 0,0 & 5200 & 0,0 \\
\hline Tocantins & 499151 & 1,1 & 1132502 & 0,9 \\
\hline Nordeste & 8198642 & 18,0 & 11388944 & 8,6 \\
\hline Maranhão & 1349138 & 3,0 & 2350187 & 1,8 \\
\hline Piauí & 924954 & 2,0 & 1451450 & 1,1 \\
\hline Ceará & 1339603 & 2,9 & 1175135 & 0,9 \\
\hline Rio Grande do Norte & 202488 & 0,4 & 133155 & 0,1 \\
\hline Paraíba & 435138 & 1,0 & 335635 & 0,3 \\
\hline Pernambuco & 631997 & 1,4 & 309846 & 0,2 \\
\hline Alagoas & 198099 & 0,4 & 120343 & 0,1 \\
\hline Sergipe & 205387 & 0,5 & 291733 & 0,2 \\
\hline Bahia & 2911838 & 6,4 & 5221460 & 3,9 \\
\hline Sudeste & 4824937 & 10,6 & 15864778 & 12,0 \\
\hline Minas Gerais & 2787128 & 6,1 & 9384673 & 7,1 \\
\hline Espírito Santo & 63696 & 0,1 & 118360 & 0,1 \\
\hline Rio de Janeiro & 19943 & 0,0 & 38468 & 0,0 \\
\hline São Paulo & 1954170 & 4,3 & 6323277 & 4,8 \\
\hline Sul & 17146181 & 37,6 & 58606878 & 44,3 \\
\hline Paraná & 8491460 & 18,6 & 30138519 & 22,8 \\
\hline Santa Catarina & 1469234 & 3,2 & 6219558 & 4,7 \\
\hline Rio Grande do Sul & 7185487 & 15,8 & 22248801 & 16,8 \\
\hline Centro-Oeste & 13787828 & 30,2 & 42967193 & 32,5 \\
\hline Mato Grosso do Sul & 2733485 & 6,0 & 8456580 & 6,4 \\
\hline Mato Grosso & 7412204 & 16,3 & 22778324 & 17,2 \\
\hline Goiás & 3527220 & 7,7 & 11231759 & 8,5 \\
\hline Distrito Federal & 114919 & 0,3 & 500530 & 0,4 \\
\hline
\end{tabular}

maçãs é mais expressiva na região Sul, sendo a responsável por $99,8 \%$ da produção nacional total. Dentro dessa região, Santa Catarina é o estado maior produtor do país, com área total plantada de 19.368 ha e produção de 496.665 t. O Rio Grande do Sul, segundo maior produtor, possui área plantada de 16.140 ha e produção de 328.091 t. Em conjunto, essas duas principais áreas de cultivo de macieiras são responsáveis por mais de $95 \%$ do total de maçãs produzidas no Brasil. ${ }^{178}$

A área plantada de macieira no país, em 2005, foi de 35.327 ha. Como mostra a Figura 3, ${ }^{177}$ enquanto a área aumentou $45,18 \%$ de 1990 a 2005, a produção teve um acréscimo de 140,41\%, nesse mesmo período. A melhoria da produtividade pode ser atribuída à reconversão de pomares com porta enxertos adequados e à escolha de locais mais apropriados e de cultivares mais rentáveis com maior potencial para a exportação.

A maior parte da produção nacional de maçãs provém de duas cultivares: Gala e Fuji e suas mutações clonais. A cultivar Gala é a primeira a ser colhida, em fevereiro, com $55 \%$ da produção total; sendo que a Fuji, cuja colheita se dá em abril, é mais resistente para frigoconservação, participando com $40 \%$ da produção; os $5 \%$ restantes são referentes às cultivares Golden Delicious, Cripps Pink, Brookfield, Eva, Braeburn, entre outras. Cerca de $80 \%$ do total de maçãs produzidas são destinados ao consumo in natura, comercializadas especialmente via Centrais de Abastecimento S/A (CEASA), Compa- 


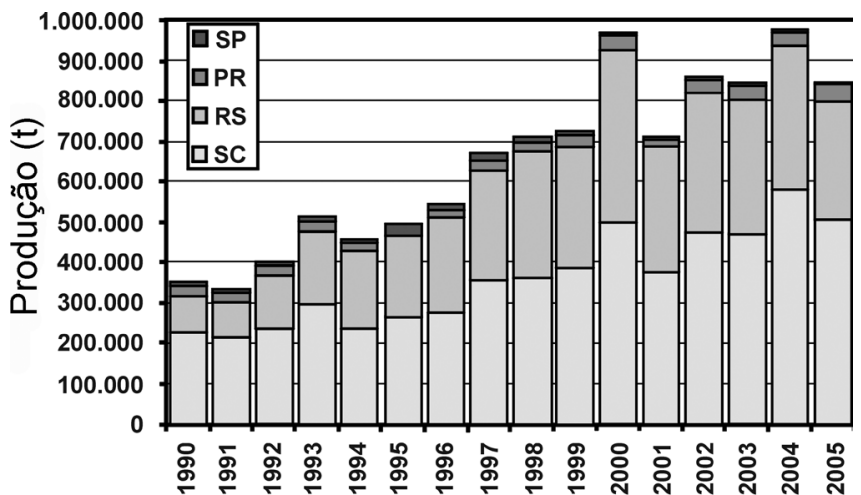

Figura 2. Produção brasileira de maçãs - dados de 1990 a 2005. Adaptada da ref. 177

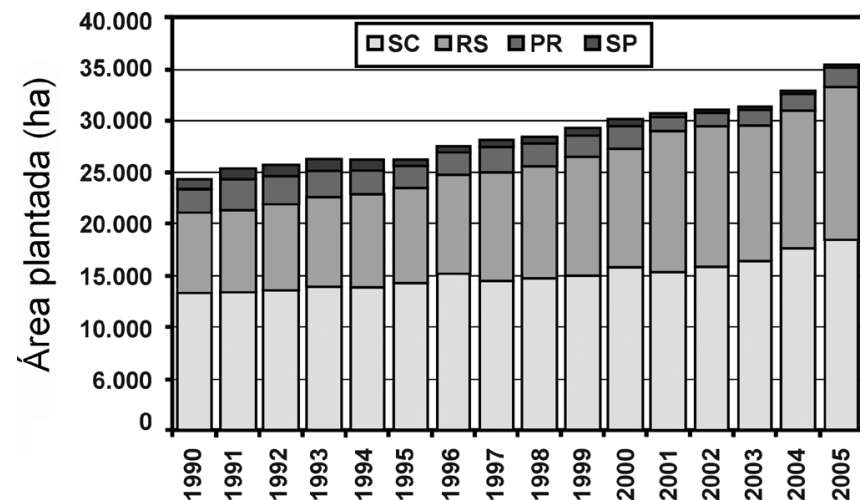

Figura 3. Área plantada de pomares de macieira no Brasil - dados de 1990 a 2005. Adaptada da ref. 177

Tabela 2. Estudo comparativo entre as safras de 2006 e 2007 - área, produção e rendimento médio das lavouras de maçãs no Brasil. Adaptada da ref. 178

\begin{tabular}{|c|c|c|c|c|c|}
\hline \multirow{2}{*}{$\begin{array}{l}\text { Grandes Regiões e } \\
\text { Unidades da Federação }\end{array}$} & \multirow{2}{*}{ Variável } & \multirow{2}{*}{ Safra 2006} & \multirow{2}{*}{ Safra 2007} & \multirow{2}{*}{$\begin{array}{c}\text { Variação em relação ao } \\
\text { mês ano anterior }(\%)\end{array}$} & \multirow{2}{*}{$\frac{\text { Participação (\%) }}{\text { Safra } 2006 \text { Safra } 2007}$} \\
\hline & & & & & \\
\hline \multirow{4}{*}{ Total } & Área I & 37621 & 36974 & $-1,7$ & 100,0 \\
\hline & Área II & 36094 & 36094 & 0,0 & 100,0 \\
\hline & Produção & 871686 & 948740 & 8,8 & 100,0 \\
\hline & Rend. Médio & 24150 & 26285 & 8,8 & - \\
\hline \multirow{4}{*}{ Sudeste } & Área I & 163 & 163 & 0,0 & 0,4 \\
\hline & Área II & 163 & 163 & 0,0 & 0,5 \\
\hline & Produção & 2080 & 2052 & $-1,3$ & 0,2 \\
\hline & Rend. Médio & 12761 & 12589 & $-1,3$ & - \\
\hline \multirow{4}{*}{ São Paulo } & Área I & 163 & 163 & 0,0 & 0,4 \\
\hline & Área II & 163 & 163 & 0,0 & 0,5 \\
\hline & Produção & 2080 & 2052 & $-1,3$ & 0,2 \\
\hline & Rend. Médio & 12761 & 12587 & $-1,4$ & - \\
\hline \multirow{4}{*}{ Sul } & Área I & 37458 & 36811 & $-1,7$ & 99,6 \\
\hline & Área II & 35931 & 35931 & 0,0 & 99,5 \\
\hline & Produção & 869606 & 946688 & 8,9 & 99,8 \\
\hline & Rend. Médio & 24202 & 26347 & 8,9 & - \\
\hline \multirow{4}{*}{ Paraná } & Área I & 1950 & 1950 & 0,0 & 5,2 \\
\hline & Área II & 1950 & 1950 & 0,0 & 5,4 \\
\hline & Produção & 44850 & 43956 & $-2,0$ & 5,1 \\
\hline & Rend. Médio & 23000 & 22542 & $-2,0$ & - \\
\hline \multirow{4}{*}{ Santa Catarina } & Área I & 19368 & 18721 & $-3,3$ & 51,5 \\
\hline & Área II & 18721 & 18721 & 0,0 & 51,9 \\
\hline & Produção & 496665 & 538516 & 8,4 & 57,0 \\
\hline & Rend. Médio & 26530 & 28765 & 8,4 & - \\
\hline \multirow{4}{*}{ Rio Grande do Sul } & Área I & 16140 & 16140 & 0,0 & 42,9 \\
\hline & Área II & 15260 & 15260 & 0,0 & 42,3 \\
\hline & Produção & 328091 & 364216 & 11,0 & 37,6 \\
\hline & Rend. Médio & 21500 & 23867 & 11,0 & - \\
\hline
\end{tabular}

Notas: Área I: área total plantada (ha); Área II: área a ser colhida (ha); Produção (t) e Rendimento Médio (kg ha-1). 
nhia de Entrepostos e Armazéns Gerais de São Paulo (CEAGESP) e grandes supermercados. As maçãs destinadas à agroindústria são de qualidade inferior e não apresentam condições de serem comercializadas no mercado da fruta in natura, a não ser quando esse mercado não esteja saturado. Atualmente, o cultivo de maçãs no Brasil é realizado por mais de 2.300 produtores, no entanto, a maior parte da produção dessas frutas provém de grandes empresas, que cultivam extensas áreas, com nível avançado de integração vertical nas estruturas de classificação, de câmaras frias e de comercialização. ${ }^{179}$

\section{A IMPORTÂNCIA DA DETERMINAÇÃO DE RESÍDUOS DE AGROTÓXICOS EM MAÇÃS}

Até a década de 70, o Brasil importava praticamente toda a maçã consumida. $\mathrm{O}$ aumento da produção permitiu ao Brasil substituir gradativamente as importações na década de 80 e início da década de 90 , tornando-se atualmente autossuficiente na produção deste alimento. $\mathrm{O}$ Brasil passou, então, de tradicional importador para exportador, com saldo positivo no comércio internacional de maçãs. ${ }^{180,181}$

Em vista das informações expostas no presente artigo, além dos dados do IBGE referentes à produção de maçãs no Brasil, nota-se que a extensão de áreas plantadas e também o consumo dessa fruta vêm sofrendo uma tendência de aumento nos últimos anos. Constata-se que, no âmbito internacional, a produção de maçãs, anualmente, é cerca de 42,4 milhões de t, figurando a China como a maior produtora mundial, com 16,7 milhões de ano $^{-1} .{ }^{182}$ Essa elevada produção tem feito com que as maçãs sejam comercializadas a um custo popular e, desta maneira, são exportadas e consumidas dentro do país em grandes quantidades.

Em um mercado competitivo, as maçãs, assim como qualquer outra fruta, geralmente, comercializadas in natura, devem possuir qualidade para que sejam aceitas pelo consumidor. Todavia, há vários parâmetros para a avaliação da qualidade e segurança de uma fruta. Dentre os mais relevantes, destacam-se a presença de resíduos de agrotóxicos com risco potencial à saúde humana, além de propriedades nutricionais e características organolépticas de cor e odor, que são fatores considerados indispensáveis na avaliação da qualidade de frutas. A aparência da fruta também é um parâmetro considerado importante, sendo um dos principais quesitos classificatórios, porém, nem sempre um fruto de boa aparência é seguro para o consumo, principalmente em se tratando de resíduos de agrotóxicos. Deve-se enfatizar que frutas, como as maçãs, são consumidas quase na totalidade com a ingestão da casca, às vezes sem lavagens adequadas, que expõe em muito as pessoas aos riscos de contaminação com resíduos de agrotóxicos. ${ }^{183}$

Em função do consumo elevado de maçãs, observa-se que estudos com essas frutas vêm merecendo atenção especial, principalmente, devido aos benefícios ${ }^{184-192}$ e, ao mesmo tempo, aos riscos que a ingestão destas pode causar à saúde humana. Em suma, o aumento do consumo de maçãs contendo resíduos de agrotóxicos, somado ao desconhecimento da toxicidade crônica em humanos, tanto no âmbito nacional quanto no internacional, pode causar danos à saúde pública. Todavia, tal ameaça tem despertado grandes interesses de diversos pesquisadores sobre o tema, inclusive os da área acadêmica, além de órgãos legisladores e de controle ambiental. ${ }^{193,194}$

Embora alguns dos resíduos de agrotóxicos encontrados em alimentos não excedam os limites máximos permitidos para o consumo humano, ao longo prazo, ainda não se conhecem os efeitos da acumulação desses compostos no organismo humano. Por exemplo, não foi calculado o efeito crônico dos agrotóxicos em crianças e bebês. O que se conhece até o momento é que muitos agrotóxicos podem causar câncer ou outros efeitos adversos em animais, humanos e no meio ambiente. ${ }^{195,196}$ Por isso, muitos agrotóxicos foram banidos em diversos países, mas, a utilização ilegal desses compostos ainda tem sido relatada.
A macieira é uma cultura perene, de ciclo longo e sujeita ao ataque de várias pragas e doenças. Por isso, muitos tratamentos fitossanitários tornam-se necessários, principalmente a aplicação de fungicidas e inseticidas. No entanto, observa-se que a produção de maçãs é, a cada safra, comprometida pela ação de pragas, com destaque para os insetos denominados tortricídeos Bonagota cranaodes e Grafolita molesta ${ }^{197,198}$ Adicionalmente, observa-se que, através do processo de seleção natural, as pragas podem se tornar muito resistentes à ação de um determinado tipo de agrotóxico e, consequentemente, os agricultores tendem a aumentar a quantidade do agrotóxico usado, intensificando ainda mais os problemas discutidos.

A preocupação com a presença de agrotóxicos nos alimentos é tão antiga quanto a introdução desses químicos no controle de pragas e doenças que afetam a produção agrícola. Entretanto, foi somente em anos mais recentes que o avanço do conhecimento científico aliado ao desenvolvimento tecnológico na área laboratorial vêm permitindo, no âmbito das diferentes esferas de governo, a estruturação de serviços para a verificação da segurança dos alimentos em relação à presença de agrotóxicos. Ao longo da última década o monitoramento de resíduos de agrotóxicos em alimentos, em alguns países, tem se constituído em múltiplos esforços isolados entre algumas instituições de pesquisas e órgãos estaduais de saúde e agricultura. ${ }^{199}$ Desta forma, foi necessário discutir o desenvolvimento de estratégias de monitoramento que otimizassem a atuação desses órgãos e permitissem à população, dentre outras coisas, a melhor visibilidade quanto a qualidade dos alimentos consumidos em relação ao nível de contaminação por agrotóxicos.

Por exemplo, o USDA dos Estados Unidos desenvolveu um programa chamado Pesticide Data Program que teve como objetivo verificar os índices de alimentos contaminados por resíduos de agrotóxicos. Com início em 1990, os pesquisadores responsáveis por esse programa coletaram dados de, aproximadamente, 60 tipos diferentes de alimentos e cerca de 400 tipos de agrotóxicos, cujas amostras eram obtidas diretamente nos locais de venda ao consumidor final. Os primeiros resultados do programa foram divulgados somente em 2004, sendo que as principais decorrências, obtidas a partir da análise de frutas supostamente contaminadas com resíduos de agrotóxicos, são apresentadas, resumidamente, na Tabela $3 .{ }^{200}$ Dentre as amostras analisadas, serão apresentados dados de maçã, alface, pera e suco de laranja.

Tabela 3. Resultados da determinação de resíduos de agrotóxicos em amostras de frutas. Adaptada da ref. 200

\begin{tabular}{lccccc}
\hline Amostra & $\begin{array}{c}\text { Amostras } \\
\text { analisadas }\end{array}$ & $\begin{array}{c}\text { Amostras } \\
\text { com } \\
\text { resíduos } \\
\text { detectados }\end{array}$ & $\begin{array}{c}\text { Amostras } \\
\text { contami- } \\
\text { nadas } \\
(\%)\end{array}$ & $\begin{array}{c}\text { Agrotóxicos } \\
\text { detectados }\end{array}$ & $\begin{array}{c}\text { Resíduos } \\
\text { detectados }\end{array}$ \\
\hline$\underline{\text { Maçã }}$ & $\underline{774}$ & $\underline{727}$ & $\underline{94}$ & $\underline{33}$ & $\underline{41}$ \\
Alface & 743 & 657 & 88 & 47 & 57 \\
Pera & 741 & 643 & 87 & 31 & 35 \\
$\begin{array}{l}\text { Suco de } \\
\text { laranja }\end{array}$ & 186 & 93 & 50 & 3 & 3 \\
\hline
\end{tabular}

Como mostra a Tabela 3, dentre as amostras analisadas, as maçãs foram as que apresentaram maior porcentagem de contaminação por resíduos de agrotóxicos. Nesse caso, das 774 amostras de maçãs analisadas, mais de 94\% (727 amostras) estavam contaminadas por, pelo menos, um tipo de resíduo de agrotóxico. Ainda nessas amostras foram encontrados 33 diferentes tipos de agrotóxicos, com 41 diferentes resíduos (princípio ativo) de agrotóxicos. ${ }^{200}$ Os cenários apresentados remetem à necessidade urgente do estabelecimento de 
programas que monitorem resíduos de agrotóxicos em diferentes meios afetados, principalmente em alimentos consumidos in natura e processados, como é o caso específico das maçãs. Os dados da Tabela 3 revelam a realidade vivenciada atualmente pela comunidade, o que demonstra, de fato, que os agrotóxicos podem apresentar riscos eminentes para a população mundial, especialmente para os consumidores de maçãs. Todavia, o emprego desses compostos oferece ameaça não somente aos consumidores, mas também aos trabalhadores que mantêm contato direto ou indireto durante a manufatura e o transporte desses produtos químicos. Além disso, o uso de agrotóxicos na agricultura, para controle de pragas, também pode oferecer riscos aos trabalhadores rurais.

De forma geral, tendo em vista, principalmente, as consequências ambientais e de saúde pública enfrentadas não somente no Brasil, mas em vários outros países, cujas relações estão ligadas em maior parte com a concentração de resíduos de agrotóxicos encontrados em alimentos, é de suma importância a realização de trabalhos que dêem um enfoque geral à problemática relacionada aos efeitos desses compostos quando presentes na forma de resíduos nos frutos da macieira. Por esses motivos, constata-se que a realização de programas nacionais de monitoramento de resíduos de agrotóxicos em alimentos é fundamentalmente importante para a sociedade como um todo. Desse modo, estudos relacionados à determinação de resíduos de agrotóxicos no fruto da macieira contribuem, por exemplo, para que ações de órgãos de vigilância sanitária, como a ANVISA, com foco na prevenção e controle dos riscos à saúde humana decorrentes do consumo de alimentos contaminados, sejam desenvolvidas. ${ }^{201}$

\section{AGROTÓXICOS MAIS UTILIZADOS NA PRODUÇÃO DE MAÇÃS NO BRASIL}

A ANVISA iniciou em 2001, um projeto denominado Projeto de Análise de Resíduos de Agrotóxicos em Alimentos (PARA), ${ }^{202} \mathrm{O}$ qual visa avaliar a qualidade dos alimentos em relação aos usos de agrotóxicos. O Projeto foi transformado em Programa, através da RDC ${ }^{\circ} \cdot 119$, de 19 de maio de 2003, e veio de encontro aos anseios dos profissionais voltados à melhoria da qualidade de vida da população, bem como da própria sociedade, fornecendo uma ferramenta apta para garantir a qualidade e a segurança alimentar no que tange aos resíduos de agrotóxicos. Para isso, a ANVISA elaborou o Projeto e definiu a logística das ações em articulação com as Coordenações de Vigilância Sanitária de diversos estados brasileiros. Até 2007, participaram do PARA as Vigilâncias Sanitárias dos estados do Acre, Alagoas, Amazonas, Bahia, Distrito Federal, Espírito Santo, Goiás, Maranhão, Mato Grosso do Sul, Minas Gerais, Pará, Paraíba, Paraná, Pernambuco, Piauí, Rio de Janeiro, Rio Grande do Norte, Rio Grande do Sul, Rondônia, Santa Catarina, São Paulo, Sergipe e Tocantins; além do Departamento de Inspeção Municipal de Alimentos do município de São Paulo, dos laboratórios de resíduos de agrotóxicos do Instituto Adolfo Lutz (IAL - SP), Instituto Octávio Magalhães (IOM/ FUNED - MG), Instituto Tecnológico de Pernambuco (ITEP - PE) e, ainda, do Laboratório Central do Paraná (LACEN - PR) com o apoio da Fundação Oswaldo Cruz, e o Instituto Nacional de Controle e Qualidade em Saúde (FIOCRUZ/INCQS - RJ). ${ }^{202}$

Diversos países, como Estados Unidos, Holanda, Suécia e Inglaterra, têm estabelecido programas de monitoramento de resíduos de agrotóxicos, com análises contínuas e programadas. Pode-se afirmar que, atualmente, é frequente a identificação de resíduos de agrotóxicos em alimentos ${ }^{31,38,141,194,203} \mathrm{e}$, em muitos casos, dentre os alimentos produzidos e comercializados nesses países é possível detectar concentrações de resíduos bem acima dos limites máximos permitidos, além daqueles não autorizados.
Recentemente, trabalhos desenvolvidos pela ANVISA em conjunto com as vigilâncias sanitárias e os laboratórios mencionados anteriormente têm demonstrado que essa realidade também se repete em nosso país. Isso pode ser comprovado pelos resultados do PARA, através de pesquisas interlaboratoriais realizadas entre 2001 e 2006 em diversos estados brasileiros. As análises foram feitas, em cerca de 2.000 amostras por ano, através do monitoramento de resíduos de agrotóxicos em 9 tipos de alimentos in natura: alface, banana, batata, cenoura, laranja, maçã, mamão, morango e tomate. ${ }^{202} \mathrm{O}$ histórico das irregularidades encontradas permite concluir que o maior problema no tocante aos níveis de resíduos de agrotóxicos nos alimentos não está somente na forma de aplicação do produto na cultura e dos limites permitidos, mas sim, no uso indiscriminado de agrotóxicos não autorizados para as culturas.

A análise dos resultados do PARA, obtidos através de estudos realizados entre julho de 2001 e dezembro de 2004 em amostras de maçãs in natura, mostrou que os resíduos de agrotóxicos mais encontrados em 395 amostras analisadas foram: azinfós metílico, carbaril, clorpirifós metílico, clorpirifós, diclorvós, dicofol, dimetoato, ditiocarbamatos, fenitrotiona, folpete, metidationa e pirimifós metílico. Dentre os agrotóxicos citados, carbaril, clorpirifós, dicofol, dimetoato, ditiocarbamatos, fenitrotiona e pirimifós metílico foram encontrados em quantidades expressivas em grande parte das amostras analisadas. Os compostos cujos grupos químicos fazem parte dos ditiocarbamatos foram os mais detectados em amostras de maçãs. ${ }^{202}$

Até o momento, o Brasil não dispõe à consulta pública dados oficiais contendo informações sobre os tipos de agrotóxicos mais utilizados pelos agricultores em culturas de maçãs. Contudo, de acordo com Botton, pesquisador da Empresa Brasileira de Pesquisa Agropecuária (EMBRAPA Uva e Vinho), que trabalha diretamente com o manejo de pragas em culturas da macieira, dentre os agrotóxicos permitidos, os mais empregados em 2007, para esse tipo de cultura em plantações brasileiras, foram: inseticidas - clorpirifós etílico, fenitrotiona, fosmete, malationa (malatol) e metidationa e, fungicidas - captam e mancozebe. ${ }^{204}$

A determinação de resíduos de agrotóxicos em maçãs de origem brasileira foi relatada recentemente por alguns pesquisadores. ${ }^{205,206}$ Normalmente os estudos têm sido divididos em três condições, nas quais são feitas análises de amostras de frutos inteiros, na casca e na polpa. Na maioria das pesquisas, foram encontrados resíduos dos seguintes agrotóxicos organofosforados: fenitrotiona, metidationa, fentiona, diazinona, etiona, pirazofós e clorpirifós, todos enquadrados como compostos de classificação toxicológica I e II, e de uso registrado para a cultura de maçãs. O composto metidationa foi o que apresentou maiores concentrações nas amostras analisadas. As pesquisas brasileiras também revelam que resíduos dos agrotóxicos clorpirifós, metidationa e ditiocarbamatos têm sido encontrados, com frequência, na análise de amostras de maçãs. Sharma e Nath, em um Estado da Índia, também avaliaram a presença de resíduos de agrotóxicos em maçãs. Os compostos estudados foram carbendazim, mancozebe, dodina, endosulfam, clorpirifós, parationa metílico, diclorvós, lindano, fenazaquina, bitertanol, miclobutanil e antracol. Outros agrotóxicos bastante empregados no cultivo de maçãs são: aldicarbe, aldicarbe-sulfom, imazalil, iprodiona, malationa, metomil, pirimifós metílico, fosalona e tiabendazol. ${ }^{207}$

\section{CONSIDERAÇÕES FINAIS}

Em vista das temáticas abordadas na presente revisão sobre os agrotóxicos e o seu emprego no cultivo de diversos alimentos, ilustrando a toxicidade e a acumulação desses compostos em diversos compartimentos ambientais, sobretudo nos seres humanos, conclui-se que é de suma importância a realização de pesquisas que esclareçam 
à sociedade a pertinência do desenvolvimento de programas que monitorem resíduos de agrotóxicos em alimentos. Nesse contexto, as pesquisas revelam que quantidades significativas de resíduos de agrotóxicos têm sido encontradas em diversos tipos de culturas consumidas, na maioria das vezes, na forma in natura. Neste caso, uma atenção especial deve ser dada às maçãs, pois, além de serem consumidas por diversas pessoas, algumas destas apresentam quantidades expressivas de agrotóxicos, de diferentes classes e em diferentes concentrações. Ressalta-se que a situação atual e particular do Brasil pode ser confirmada, especialmente, por dados recentes publicados pela ANVISA e pelo IBGE. Os dados referentes à produção de maçãs no Brasil mostram que, ao longo dos anos, se nota que a extensão de áreas plantadas e, também, o consumo dessas frutas vêm sofrendo um aumento constante. Adicionalmente, as pesquisas revelam que a determinação de agrotóxicos em maçãs tem despertado o interesse de vários pesquisadores. Tal interesse pode ser explicado por alguns fatores, por exemplo, pela carência de estudos relacionados aos efeitos da exposição crônica a essas substâncias, associados ao consumo elevado de maçãs.

De forma geral, a variedade desses compostos associada à toxicidade e aos efeitos adversos, possivelmente causados pelo consumo de frutas e verduras contaminadas, devem ser um alerta à população. Em consequência, a comunidade científica vem despertando o interesse em desenvolver estudos que abordem tanto os efeitos adversos sobre a saúde das pessoas, como a validação de métodos analíticos para a determinação de multirresíduos de agrotóxicos nessas amostras. Nesse contexto, a determinação de multirresíduos com limites de quantificação cada vez menores é um desafio aos pesquisadores, sendo que os estudos devem ser extrapolados ao maior número de composto e de matrizes ambientais, principalmente com relação aos alimentos consumidos in natura.

\section{AGRADECIMENTOS}

Ao CNPq e à FAPESP pelo apoio financeiro concedido.

\section{REFERÊNCIAS}

1. Companhia de Tecnologia de Saneamento Ambiental (CETESB); Relação de áreas contaminadas no Estado de São Paulo, Novembro de 2007. http://www.cetesb.sp.gov.br/, acessada em Julho 2008.

2. Andrade, J. A.; Dissertação de Mestrado, Universidade Estadual de Campinas, Brasil, 2005.

3. Schwarzenbach, R. P.; Gschwend, P. M.; Imboden, D. M.; Environmental Organic Chemistry, Wiley-Interscience: USA, 1995.

4. Ministerial Decree 2002/5/EC e Council Directive 90/642/EEC; Maximum levels for pesticide residues in and on certain products of plant origin, including fruit and vegetables, 2002. http://www.ipfsaph.org/En/ default.jsp, acessada em Julho 2008.

5. Food and Agriculture Organization of the United Nations (FAOUN); Pesticide residues in food, 2006. http://www.fao.org/, acessada em Julho 2008.

6. FAOUN; Maximum Residue Limit (MRL), 2007. http://www.fao.org/, acessada em Julho 2008.

7. International Portal on Food Safety, Animal \& Plant Health (IPFSAPH); MRLs for pesticides, 2007. http://www.ipfsaph.org/servlet/CDSServlet?class=org.fao. waicent.cds.KOSearchResults\&org. fao.waicent.cds. KOSearchResults.0.query=dcsubjectissue:httpwwwfaoorgaosipfsaphissuekeywordspesticideresidues $\% 20$ AND\%20dctype:httpwwwfaoorgaosinformationtypemaximumresiduelimit, acessada em Julho 2008.

8. IPFSAPH; Pesticide Residues, other than MRLs, 2007. http://www.ipfsaph. org/servlet/CDSServlet?class=org.fao.waicent.cds.KOSearchResults\&org.
fao.waicent.cds.KOSearchResults.0.query=(pesticide*residue*NOTdctyp e:httpwwwfaoorgaosinformationtypemaximumresiduelimit), acessada em Julho 2008.

9. World Health Organization (WHO); Pesticide residues in food, Itália, Outubro 2006. http://www.who.int/en/, acessada em Julho 2008.

10. Fernandez-Cruz, M. L.; Grimalt, S.; Villarroya, M.; Lopes, F. J.; Llanos, S.; Garcia-Baudin, J. M.; Food Addit. Contam. 2006, 23, 591.

11. Sannino, A.; Bandini, M.; J. AOAC Int. 2005, 88, 1822.

12. Hirahara, Y.; Kimura, M.; Inoue, T.; Uchikawa, S.; Otani, S.; Hirose, H.; Suzuki, S.; Uchida, Y.; J. Food Hyg. Soc. Jpn. 2006, 47, 225.

13. Fernandez, M.; Rodríguez, R.; Picó, Y.; Mañes, J.; J. Chromatogr., A 2001, 912, 301.

14. Zamora, T.; Pozo, O. J.; López, F. J.; Hernández, F.; J. Chromatogr., A 2004, 1045, 137.

15. Hu, R. W.; Hennion, B.; Urruty, L.; Montury, M.; Food Addit. Contam. 1999, 16, 111

16. Rodríguez, R.; Picó, Y.; Font, G.; Mañes, J.; J. Chromatogr., A 2002, 949, 359 .

17. Rodríguez, R.; Picó, Y.; Font, G.; Mañes, J.; J. Chromatogr., A 2001, 924, 387.

18. Faria, A. M.; Maldaner, L.; Santana, C. C.; Jardim, I. C. S. F.; Collins, C. H.; Anal. Chim. Acta 2007, 582, 34.

19. Barker, S. A.; J. Chromatogr., A 2000, 880, 2443.

20. Fernandez, M.; Picó, Y.; Mañes, J.; J. Chromatogr., A 2000, 871, 43.

21. Blasco, C.; Picó, Y.; Font, G.; Mañes, J.; J. Chromatogr., A 2002, 984 , 227.

22. Blasco, C.; Picó, Y.; Mañes, J.; Font, G.; J. Chromatogr., A 2002, 947, 227

23. Navarro, M.; Picó, Y.; Marin, R.; Mañes, J.; J. Chromatogr., A 2002, 968 , 201.

24. Faria, A. M.; Dardengo, R. D.; Lima, C. F.; Neves, A. A.; Queiroz, M. E. L. R.; Int. J. Environ. Anal. Chem. 2007, 87, 249.

25. Faria, A.M.; Queiroz, M. E. L. R.; Neves, A. A.; Pesticidas: Revista de Ecotoxicologia e Meio Ambiente 2005, 15, 29.

26. Anastassiades, M.; Lehotay, S. J.; Stajnbaher, D.; Schenck, F. J.; J. AOAC Int. 2003, 86, 412.

27. Lehotay, S. J.; De Kok, A.; Hiemstra, M.; J. AOAC Int. 2005, 88, 595.

28. Majors, R. E.; LCGC North Am. 2007, 25, 436.

29. Lehotay, S. J.; J. AOAC Int. 2007, 90, 485.

30. Cunha, S. C.; Lehotay, S. J.; Mastovska, K.; Fernandes, J. O.; Beatriz, M.; Oliveira, P. P.; J. Sep. Sci. 2007, 30, 620.

31. Schenck, F. J.; Hobbs, J. E.; Bull. Environ. Contam. Toxicol. 2004, 73, 24.

32. García-Reyes, J. F.; Ferrer, C.; Gómez-Ramos, M. J.; Molina-Díaz, A.; Fernández-Alba, A. R.; TrAC, Trends Anal. Chem. 2007, 26, 239.

33. Polati, S.; Bottaro, M.; Frascarolo, P.; Gosetti, F.; Gianotti, V.; Gennaro, M. C.; Anal. Chim. Acta 2006, 579, 146.

34. Kovalczuk, T.; Jech, M.; Poustka, J.; Hajslová, J.; Anal. Chim. Acta 2006, 577,8 .

35. Picó, Y.; Fernández, M.; Ruiz, M. J.; Font, G.; J. Biochem. Biophys. Methods 2007, 70, 117.

36. Wang, S.; Xu, Y.; Pan, C.; Jiang, S.; Liu, F.; Anal. Bioanal. Chem. 2007, 387, 673 .

37. Watanabe, E.; Baba, K.; Heesoo, E.; Miyake, S.; Food Chem. 2007, 102, 745.

38. Zywitz, D.; Anastassiades, M.; Scherbaum, E.; Deutsche LebensmittelRundschau 2004, 100, 140.

39. Rawn, D. F. K.; Cao, X. L.; Doucet, J.; Davies, D. J.; Sun, W.-L.; Dabeka, K. W.; Newsome, W. H.; Food Addit. Contam. 2004, 21, 232.

40. Perez, A.; Lin, B-H.; Allshouse, J.; Fruit and Tree Nuts Situation and Outlook Yearbook 2001, FTS-292, 37.

41. Lewis, N. M.; Ruud, J.; Nutr. Clin. Care 2004, 1.

42. U.S. Apple Association, 2008. http://www.usapple.org/, acessada em Julho 2008. 
43. Bazzano, L. A.; He, J.; Ogden, L. G.; Loria, C. M.; Whelton, P. K.; Arch. Intern. Med. 2003, 163, 1897.

44. Boyer, J.; Liu, R. H.; Nutr. J. 2004, 3, 5.

45. Cho, E.; Seddon, J. M.; Rosner, B.; Willett, W. C.; Hankinson, S. E.; Arch. Ophthalmol. 2004, 122, 883.

46. Dai, Q.; Borenstein, A. R.; Wu, Y.; Jackson, J. C.; Larson, E. B.; Am. J. Med. 2006, 119, 751.

47. Davis, P. A.; Polagruto, J. A.; Valacchi, G.; Phung, A.; Soucek, K.; Keen, C. L.; Gershwin, M. E.; Exp. Biol. Med. (Maywood) 2006, 231, 594.

48. Honow, R.; Laube, N.; Schneider, A.; Kessler, T.; Br. J. Nutr. 2003, 90, 295.

49. Huxley, R. R.; Neil, H. A. W.; Eur. J. Clin. Nutr. 2003, 57, 904.

50. Kern, M.; Tjaden, Z.; Ngiewih, Y.; Puppel, N.; Will, F.; Dietrich, H.; Pahlke, G.; Marko, D.; Mol. Nutr. Food Res. 2005, 49, 317.

51. Liu, R. H.; Liu, J.; Chen, B.; J. Agric. Food Chem. 2005, 53, 2341.

52. Pearson, D. A.; Tan, C. H.; German, J. B.; Life Sci. 1999, 64, 1913.

53. Puel, C.; Quintin, A.; Mathey, J.; Obled, C.; Davicco, M. J.; Lebecque, P.; Kati-Coulibaly, S.; Horcajada, M. N.; Coxam, V.; Calcif. Tissue Int. 2005, 77, 311.

54. Sable-Amplis, R.; Sicart, R.; Agid, R.; Nutr. Res. 1983, 3, 325.

55. Solovchenko, A.; Schmitz-Eiberger, M.; J. Exp. Bot. 2003, 54, 1977.

56. Suzuki, R.; Rylander-Rudqvist, T.; Ye, W.; Int. J. Cancer 2008, 122, 403.

57. van der Sluis, A. A.; Dekker, M.; Skrede, G.; J. Agric. Food Chem. 2002, 50, 7211 .

58. Powers, S.; American Chronicle 2008. http://www.americanchronicle. com/articles/65054, acessada em Julho 2008.

59. Pennycook, F. R.; Diamand, E. M.; Watterson, A.; Howard, C. V.; Int. J. Occup. Environ. Health 2004, 10, 304.

60. Boon, P. E.; van der Voet, H.; van Klaveren, J. D.; Food Addit. Contam. 2003, 20 suppl 1, S36.

61. Saenz, B. C.; Sanz, A. J.; Plaza, M. M.; Perez, C. M.; Bernal, J. G.; Food Chem. 1995, 52, 305.

62. Kittredge, J.; Pesticidas in Food, 2003. http://www.nofany.org/hottopics/ pesticidesinfood.html, acessada em Julho 2008.

63. Northeast Organic Farming Association of New York (NOFA-NY); Pesticides in Food Chart, 2008. http://nofany.org/hottopics/pesticidesinfood. pdf, acessada em Julho 2008.

64. Dubey, J. K.; Nath, A.; ISHS Acta Horticulturae 2005, 696, 79.

65. Environmental Working Group; They are wath they eat. Kids' food consumption and pesticides, 1999. http://www.mindfully.org/Food/ Are-Wath-They-Eat.htm, acessada em Julho 2008.

66. Fulgoni, V.; Fulgoni, S.; Haaga, S.; Ebert, A.; Healthcare Purchasing News 2008, April 11, 1 .

67. AvianWeb. Organic Foods; The most \& the least contaminated foods fruits, 2006. http:www.avianweb.com/organicfoods.html, acessada em Julho 2008.

68. Presidência da República, Casa Civil, Subchefia para Assuntos Jurídicos (PRCCSAJ); Lei Federal $n^{\circ} 7.802$ de 1989. http://www.planalto.gov.br/ CCIVIL_03/LEIS/L7802.htm, acessada em Julho 2008.

69. PRCCSAJ; Decreto $n^{\circ} 98.816$ de 1990. https://www.planalto.gov.br/ ccivil_03/decreto/antigos/d98816.htm, acessada em Julho 2008.

70. PRCCSAJ; Decreto $n^{\circ} 4.074$ de 2002. http://www.planalto.gov.br/ CCIVIL_03/decreto/2002/D4074.htm, acessada em Julho 2008.

71. Ware, G. W.; Whitacre, D. M.; The Pesticide Book - History of Pesticides, $6^{\text {th }}$ ed.; Meister Publication, 2004, p. 335.

72. Shepard, H. H.; The Chemistry and Action of Insecticides, $1^{\text {st }}$ ed., McGraw-Hill: New York, 1951.

73. CropLife Canada; A History of Crop Protection and Pest Control Product Use - Product and Use Patterns of Chemicals. http://www.croplife. ca/, acessada em Julho 2008.

74. Baird, C.; Química Ambiental, $2^{\mathrm{a}}$ ed., Bookman: Porto Alegre, 2002.

75. Miller, G. T.; Living in the Environment; $12^{\text {th }}$ ed., Wadsworth/Thomson Learning: Belmont, 2002.
76. Bioaromatica; The history of pyrethrum. http://www.aromatica.hr/eng/ page.asp?id=buhac\&sub=buhac3. acessada em Julho 2008.

77. Daly, H.; Doyen, J. T.; Purcell, A. H.; Introduction to insect biology and diversity, $2^{\text {nd }}$ ed., Oxford University Press: New York, 1998, Chapter 14, p. 279-300.

78. Murphy, G.; Ontario - Ministry of Agriculture, Food and Rural Affairs. Resistance Management - Pesticide Rotation, 2005. http://www.omafra. gov.on.ca/english/crops/hort/news/grower/2005/12gn05a2.htm, acessada em Julho 2008.

79. Müller, P.; Nobel Prize, 1948. http://nobelprize.org/nobel_prizes/ medicine/laureates/1948/, acessada em Julho 2008.

80. Churchill, S. W.; The Churchill Centre, 1945. http://www.winstonchurchill.org/, acessada em Julho 2008.

81. Himeidan, Y. E.; Dukeen, M. Y.; El-Rayah, El-A.; Adam, I.; Eastern Mediterranean Health J. 2004, 10, 167.

82. Bruce-Chwatt, L. J.; WHO; Bull. World Health Organization 1966, 35, 405.

83. Dukeen, M. Y.; Omer, S. M.; Bull. Entomolog. Res. 1986, 76, 451

84. El Gaddal, A. A.; Malaria and development in Africa. A cross-sectoral approach. American Association for Advancement of Science, Washington DC, 1991. http://www.aaas.org/international/africa/malaria91/index. html, acessada em Julho 2008.

85. WHO; Bull. World Health Organization 1993, 71, 281.

86. El Sayed, B. B.; Acta Tropica 2000, 75, 163

87. Petrarca, V.; Med. Veterin. Entomol. 2000, 14, 149

88. WHO; Expert committee on malaria, 20th report. WHO Technical Report Series, n. 892, Geneva, 2000. http://www.who.int/en/, acessada em Julho 2008.

89. Colling, F. H.; Bsansky, N. G. J.; Science (Washington, DC, U. S.) 1994, 264, 1874.

90. WHO; Expert Committee on Specifications for Pharmaceutical Preparations, 32th report. WHO Technical Report Series, n. 823, Geneva,1992. http://www.who.int/en/, acessada em Julho 2008.

91. Carson, R.; The Life and Legacy of Rachel Carson. http://www.rachelcarson.org/, acessada em Julho 2008.

92. Carson, R.; Silent Spring, Houghton Mifflin: Boston, 1962.

93. Quinby, G. E.; Armstrong, J. F.; Durham, W. F.; Nature 1965, 207, 726.

94. Laug, E. P.; Kunze, F. M.; Prickett, C. S.; Arch. Indust. Hyg. 1951, 3 , 245.

95. Ejobi, F.; Kanja, L. W.; Kyule, M. N.; Nyeko, J.; Opuda-Asibo, J.; Public Health 1998, 112, 425.

96. Stuetz, W.; Prapamontol, T.; Erhardt, J. G.; Classen, H. G.; Sci. Total Environ. 2001, 273, 53

97. Brunetto, R.; León, A.; Burguera, J. L.; Burguera, M.; Sci. Total Environ 1996, 186, 203.

98. Quinsey, P. M.; Donohue, D. C.; Ahokas, J. T.; Food Chem. Toxicol. 1995, 33, 49 .

99. Ennaceur, S.; Gandoura, N.; Driss, M. R.; Environ. Res. 2008, $108,86$.

100. Azeredo, A.; Torres, J. P. M.; Fonseca, M. F.; Britto, J. L.; Bastos, W. R.; Silva, C. E. A.; Cavalcanti, G.; Meire, R. O.; Sarcinellid, P. N..; Cláudio, L.; Markowitz, S.; Malm, O.; Chemosphere 2008, 73, S246.

101. Szyrwińska, K.; Lulek, J.; Chemosphere 2007, 66, 1895.

102. Environmental Defense Fund (EDF); The U.S. Ban on DDT: A Continuing Success Story, 1967. http://www.environmentaldefense.org/home. cfm, acessada em Julho 2008.

103. United States Department of Agriculture (USDA); Cropduster spraying pesticides, 2003. http://www.usda.gov/wps/portal/usdahome, acessada em Julho 2008.

104. Ministério da Agricultura; Portaria $n^{o}$ 329, de 02 de setembro de 1985.

105. Environmental Protection Agency (EPA); Pesticides, 2007. http://www. epa.gov/pesticides/, acessada em Julho 2008. 
106. Ankley, G.; Mihaich, E.; Stahl, R.; Tillitt, D.; Colborn, T.; Mcmaster, S.; Miller, R.; Bantle, J.; Campbell, P.; Denslow, N.; Dickerson, R.; Folmar, L.; Fry, M.; Giesy, J.; Gray, L. E.; Guiney, P.; Hutchinson, Th.; Kennedy, S.; Kramer, V.; LeBlanc, G.; Mayes, M.; Nimrod, A.; Patino, R.; Peterson, R.; Purdy, R.; Ringer, R.; Thomas, P.; Touart, L.; van der Kraak, G.; Zacharewski, T.; Environ. Toxicol .Chem. 1998, 17, 68.

107. Hoffman, D. J.; Rattner, B. A.; Burton Jr., G. A.; Cairns Jr., J.; Handbook of Ecotoxicology, $2^{\text {nd }}$ ed., Lewis Publishers CRC Press LLC: USA, 2003, section $\mathrm{V}$, cap. 39.

108. Lintelmann, J.; Katayama, A.; Kurihara, N.; Shore, L.; Wenzel, A.; Pure Appl. Chem. 2003, 75, 631.

109. United Nations Environment Programme; UNEP Chemicals, Global Report. Eastern and Western South America Regional Report, 2003. http://www.chem.unep.ch/pts, acessada em Julho 2008.

110. Salles Filho, S. L. M.; Tese de Doutorado, Universidade Estadual de Campinas, Brasil, 1993.

111. Schultz, T. W.; A Transformação da Agricultura Tradicional, Zahar: Rio de Janeiro, 1965.

112. Silva, J. G.; O que é Questão Agrária, 12ª ed., Brasiliense: São Paulo, 1986.

113. Silva, J. G.; A modernização dolorosa, Zahar: Rio de Janeiro, 1982.

114. Graziano Neto, F.; Questão Agrária e Ecologia - Crítica da Moderna Agricultura, $3^{\mathrm{a}}$ ed., Brasiliense: São Paulo, 1986.

115. Paulus, G.; Dissertação de Mestrado, Universidade Federal de Santa Catarina, Brasil, 1999.

116. Superintendência de Controle de Endemias (SUCEN); Formulação dos praguicidas, parte 3. http://www.sucen.sp.gov.br/, acessada em Julho 2008.

117. Instituto Brasileiro de Geografia e Estatística (IBGE); Levantamento sistemático da produção agrícola: prognóstico da produção agrícola na Região Centro-Sul e em Rondônia - anual de 1976-1981, 1982.

118. IBGE; Levantamento Sistemático da produção Agrícola: pesquisa mensal de previsão e acompanhamento das safras agrícolas no ano civil / Fundação Instituto Brasileiro de Geografia e Estatística, Jan. 1975 a Jul. 1989, 1989, 1.

119. IBGE; Censo agropecuário nacional. Dados de 1995 a 1996, Editora do IBGE: Brasil, 1998, n. 1

120. IBGE; Indicadores de desenvolvimento sustentável, . Brasil, 2004, 1.

121. WHO; Pesticides Residues in Food, 1993. Evaluations. Part II Toxicology, International Programme on Chemical Safety, Geneva, 1994. http:// www.who.int/en/, acessada em Julho 2008.

122. Vettorazzi, G.; Almeida, W. F.; Burin, G. J.; Jaeger, R. B.; Puga, F. R.; Rhade, A. F.; Reyes, F. G.; Chvartsman, S.; Teratogen., Carcinog. Mutagen. 1995, 15, 313.

123. Agência Nacional de Vigilância Sanitária (ANVISA); Programa de Análise de Resíduos de Agrotóxicos em Alimentos - PARA. Resultados Analíticos de 2002, 2003. http://www.anvisa.gov.br/toxicologia/resíduos/ rel_anual2002_an2.pdf, acessada em Dezembro 2007.

124. Caldas, E. D.; Miranda, M. C. C.; Conceição, M. H.; De Souza, L. C. K. R.; Food Chem. Toxicol. 2004, 42, 1877.

125. ANVISA; Características Físicas, Químicas e Toxicológicas de Agrotóxicos, 2008. http://www.anvisa.gov.br/toxicologia/monografias/ index.htm, acessada em Julho 2008.

126. Sindicato Nacional da Indústria de Produtos para Defesa Agrícola (SINDAG); Consumo de agrotóxicos no Brasil em 2005, 2006. http:// www.sindag.com.br/, acessada em Julho 2008.

127. National Academy of Sciences (NAS). National Research Council; Pesticides in the Diets of Infants and Children, National Academy Press: Washington, D.C., 1993.

128. ANVISA; Problemas de saúde relacionados à exposição por agrotóxicos, 2003. http://www.anvisa.gov.br/toxicologia/residuos/index. htm\#, acessada em Julho 2008.

129. Associação Brasileira de Normas Técnicas (ABNT); NBR/ISO/IEC 17025. Requisitos Técnicos para a Competência Técnica de Laboratório de Ensaios e Calibração, Rio de Janeiro, 2005.

130. Codex Alimentarius Commission; Pesticide Residues in Food. Methods of analysis and sampling, $2^{\text {nd }}$ ed., Roma, 2000, vol. 2A, part 1.

131. Arias-Estévez, M.; López-Periago, E.; Martínez-Carballo, E.; SimalGándara, J.; Mejuto, J.-C.; García-Río, L.; Agric., Ecosystems Environ. 2008, 123, 247.

132. Hildebrandt, A.; Guillamón, M.; Lacorte, S.; Tauler, R.; Barceló, D.; Water Res. 2008, 42, 3315.

133. Poissant, L.; Beauvais, C.; Lafrance, P.; Deblois, C.; Sci. Total Environ. 2008, 404, 182.

134. Baran, N.; Lepiller, M.; Mouvet, C.; J. Hydrol. 2008, 358, 56.

135. Díaz-Cruz, M. S.; Barceló, D.; Chemosphere 2008, 72, 333.

136. United States Geological Survey (USGS), NAWQA Pesticide National Synthesis Project; National assessment of pesticides in the streams, rivers, and ground water of the United States, 2007. http://www.usgs.gov/, acessada em Julho 2008.

137. Holvoet, K.; van Griensven, A.; Gevaert, V.; Seuntjens, P.; Vanrolleghem, P. A.; Environ. Modell. Software, 2008, 23, 72.

138. Gebler, L.; Banco de Informações Ambientais e Toxicológicas dos Agrotóxicos Utilizados até a Safra 2002/2003 na Produção Integrada de Maçãs no Brasil. Embrapa Uva e Vinho: Bento Gonçalves, RS, Circulação Técnica n 48, julho 2004.

139. Hill, A. R. C.; Food Addit. Contam. 2000, 17, 539.

140. IPFSAPH; Good Agriculture Practices (GAP), 2007. http://www.ipfsaph.org/ servlet/CDSServlet?class=org.fao.waicent.cds.FullTextSearchResults\&org. fao.waicent.cds.FullTextSearchResults.0.query=GAP OR "Good Agricultural Practices", acessada em Julho 2008.

141. Thurman, E. M.; Ferrer, I.; Malato, O.; Fernández-Alba, A. R.; Food Addit. Contam. 2006, 23, 1169.

142. Wang, H.; Hu, J.; Zhang, H.; Chen, C.; Chen, X.; Li, J.; Int. J. Environ. Anal. Chem. 2007, 87, 99.

143. Gupta, M.; Shanker, A.; Food Chem. 2008, 111, 805.

144. Matthies, M.; Witt, J.; Klasmeier, J.; Environ. Pollut. 2008, 156, 99.

145. Jacobson, A. R.; Dousset, S.; Guichard, N.; Baveye, P.; Andreux, F.; Environ. Pollut. 2005, 138, 250.

146. Ntow, W. J.; Tagoe, L. M.; Drechsel, P.; Kelderman, P.; Gijzen, H. J.; Nyarko, E.; Environ. Res. 2008, 106, 17.

147. Batterman, S. A.; Chernyak, S. M.; Gounden, Y.; Matooane, M.; Naidoo, R. N.; Sci. Total Environ. 2008, 397, 119.

148. Zietz, B. P.; Hoopmann, M.; Funcke, M.; Huppmann, R.; Suchenwirth, R.; Gierden, E.; Int. J. Hygiene Environ. Health 2008, 211, 624.

149. Covaci, A.; Hura, C.; Gheorghe, A.; Neels, H.; Dirtu, A. C.; Chemosphere 2008, 72, 16.

150. Ennaceur, S.; Ridha, D.; Marcos, R.; Chemosphere 2008, 71, 1335.

151. Szlinder-Richert, J.; Barska, I.; Mazerski, J.; Usydus, Z.; Mar. Pollut. Bull. 2008, 56, 927.

152. Miranda, A. L.; Roche, H.; Randi, M. A. F.; Menezes, M. L.; Ribeiro, C. A. O.; Environ. Int. 2008, 34, 939.

153. Christoforidis, A.; Stamatis, N.; Schmieder, K.; Tsachalidis, E.; Chemosphere 2008, 70, 694.

154. Muir, D.; Savinova, T.; Savinov, V.; Alexeeva, L.; Potelov, V.; Svetochev, V.; Sci. Total Environ. 2003, 306, 111.

155. Stockholm Convention; Stockholm Convention on Persistent Organic Pollutants (POPs), 2001. http://www.pops.int/, acessada em Julho 2008.

156. Senado Federal, Ministério do Meio Ambiente; Decreto Legislativo $n^{o}$ 204, de 7 de maio de 2004. http://www.mma.gov.br/, acessada em Julho 2008.

157. Birkett, J. W.; Lester, J. N.; Lintelmann, J.; Katayama, A.; Kurihara, N.; Shore, L.; Wenzel, A.; Pure Appl. Chem. 2003, 75, 631.

158. Hill, A. R. C.; Reynolds, S. L.; Food Addit. Contam. 2002, 19, 733.

159. Oga, S.; Fundamentos de Toxicologia, $1^{\text {a }}$ ed., Editora Atheneu: São Paulo, 1996. 
160. Jantunen, A. P. K.; Tuikka, A.; Akkanen, J.; Kukkonen, J. V. K.; Ecotoxicol. Environ. Saf. 2008, 71, 860.

161. Singh, P. B.; Singh, V.; Environ. Toxicol. Pharmacol. 2008, 25, 342.

162. Fundação Nacional de Saúde, Ministério da Saúde; Guia Brasileiro de Vigilância Epidemiológica, 1998.

163. Manahan, S. E.; Environmental Chemistry, $7^{\text {th }}$ ed., CRC Press LLC: USA, 2000.

164. Manahan, S. E.; Fundamentals of Environmental Chemistry, $2^{\text {nd }}$ ed., Lewis Publishers CRC Press LLC: USA, 2001.

165. U.S. Department of Health and Human Services Agency for Toxic Substances and Disease Registry Division of Toxicology, In Cooperation with the U.S. Environmental Protection Agency; CERCLA Priority List of Hazardous Substances, November 2005. http://www.epa.gov/, acessada em Julho 2008.

166. Casarini, D. C. P.; Dias, C. L.; Lemos, M. M. G.; CETESB - Relatório de estabelecimento de valores orientadores para solos e águas subterrâneas no Estado de São Paulo, 2001.

167. CETESB; Relatório de qualidade das águas subterrâneas no Estado de São Paulo 2001-2003, São Paulo, 2004.

168. CETESB; Relatório de Estabelecimento de Valores Orientadores para Solos e Águas Subterrâneas no Estado de São Paulo. Decisão de Diretoria $n^{\circ}$ 195-2005-E, de 23 de novembro de 2005, 2005.

169. ANVISA; Resolução da Diretoria Colegiada (RDC) $n^{\circ} 216$, de 15 de dezembro de 2006, 2006.

170. IBGE; Levantamento Sistemático da produção Agrícola: pesquisa mensal de previsão e acompanhamento das safras agrícolas no ano civil, Fundação Instituto Brasileiro de Geografia e Estatística, 2007, 18, 1. http://www.ibge.gov.br/home/estatistica/indicadores/agropecuaria/ lspa/default.shtm, acessada em Julho 2008.

171. Grupo de Coordenação de Estatísticas Agropecuárias do IBGE (GCEA/IBGE), Diretoria de Pesquisas, Coordenação de Agropecuária; Levantamento Sistemático da Produção Agrícola, Abril de 2007, 2007.

172. Zardo, D. M.; Dissertação de Mestrado, Universidade Estadual de Ponta Grossa, Brasil, 2007.

173. De Mello, L. M. R.; Produção e mercado da maçã brasileira, Embrapa Uva e Vinho, Circular Técnica nº 64, Bento Gonçalves, RS, 2006.

174. PRCCSAJ. Ministerio da Fazenda. Meio Ambiente; Lei Ordinária $n^{o}$ 5.106 de 1966. https://legislacao.planalto.gov.br/LEGISLA/Legislacao. $\mathrm{nsf} / \mathrm{fraWeb}$ ? OpenFrameSet $\&$ Frame $=$ frmWeb $2 \&$ Src $=\% 2$ FLEGISLA $\% 2$ FLegislacao.nsf\%2FviwTodos\%2F6131eae7ef368a3e032569fa0072fd5 5\%3FOpenDocument $\% 26$ Highlight $\% 3 \mathrm{D} 1 \% 2 \mathrm{Cfiscais} \% 26$ AutoFramed, acessada em Julho 2008.

175. Brandt, M.; Acumulação de capital no setor macieiro e continuidade política em Fraiburgo na década de 1960. UNESC: Florianópolis, 2004.

176. IBGE; Pesquisa mensal de previsão e acompanhamento das safras agrícolas no ano civil: janeiro 2005. Levantamento Sistemático da Produção Agrícola, 2005, 17, 1.

177. IBGE; Dados da produção agrícola no Brasil, 2006. http://www.ibge. gov.br/home/default.php, acessada em Julho 2008.

178. GCEA/IBGE, Diretoria de Pesquisas, Coordenação de Agropecuária; Levantamento Sistemático da Produção Agrícola, Janeiro de 2007, 2007.

179. Associação Brasileira de Produtores de Maçã (ABPM); Dados estatísticos sobre a cultura da macieira. http://www.abpm.org.br/, acessada em Julho 2008.
180. Wosiacki, G.; Nogueira, A.; Silva, N. C.; Fruit Process. 2000, 12, 472.

181. Wosiacki, G.; Nogueira, A.; Fruit Process. 2001, 11, 177.

182. Wosiacki, G.; Fruit Process. 2002, 12, 19

183. Ticha, J.; Hajslova, J.; Jech, M.; Honzicek, J.; Lacina, O.; Kohoutkova, J.; Kocourek, V.; Lansky, M.; Kloutvorova, J.; Falta, V.; Food Control 2008, 19, 247.

184. Cliff, M.; Dever, M. C.; Gayton, R.; J. Food Sci. 1991, 56, 1614.

185. Lea, A. G. H.; Timberlake, C. F.; J. Sci. Food Agric. 1978, 29, 484.

186. Lea, A. G.; Arnold, G. M.; J. Sci. Food Agric. 1978, 29, 478.

187. Lee, C. Y.; Smith, N. L.; N. Y. Fruit Q. 2000, 8, 15.

188. Mangas, J. J.; Rodriguez, R.; Suarez, B.; Picinelli, A.; J. Agric.Food Chem. 1999, 47, 4046

189. Nicolas, J. J.; Richard-Forget, F. C.; Goupy, P. M.; Amiot, M. J.; Crit. Rev. Food Sci. Nutr. 1994, 34, 109

190. Schols, H. A.; Intveld, P. H.; Vandeelen, W.; Voragen, A. G. J.; Z. Lebensmittel - Untersuch. Forsch. 1991, 192, 142

191. Will, F.; Bauckhage, K.; Dietrich, H.; Eur. Food Res. Technol. 2000, 211 , 291.

192. Nogueira, A.; Santos, L. D.; Wiecheteck, F. V. B.; Guyot, S.; Wosiacki, G.; Ci. Agr. Eng. 2003, 9, 7.

193. Rawn, D. F. K.; Quade, S. C.; Shields, J. B.; Conca, G.; Sun, W.-F.; Lacroix, G. M. A.; Smith, M.; Fouquet, A.; Bélanger, A.; J. Agric.Food Chem. 2006, 54, 1943

194. Rawn, D. F. K.; Quade, S. C.; Shields, J. B.; Conca, G.; Sun, W.-F.; Lacroix, G. M. A.; Smith, M.; Fouquet, A.; Bélanger, A.; Food Addit. Contam. 2007, 24, 149

195. McDuffie, H. H.; Pahwa, P.; McLaughlin, J. R.; Spinelli, J. J.; Fincham, S.; Dosman, J. A.; Robson, D.; Skinnider, L. F.; Choi, N. W.; Cancer Epidemiology, Biomarkers and Prevention 2001, 10, 1155.

196. Frampton, G. K.; Dorne, J. L. C. M.; J. Appl. Ecol. 2007, 44, 362.

197. Kovaleski, A.; Nickel, O.; Sanhueza, R. M. V.; Maçã: Fitossanidade, Coleção Frutas do Brasil. Ministério da Agricultura, Pecuária e Abastecimento, Embrapa Uva e Vinho, 2004. Apud ref. 198.

198. Manzoni, C. G.; Grützmacher, A. D.; Giolo, F. P.; Härter, W. R.; Muller, C.; Pesq. Agropec. Bras. 2006, 41, 1461.

199. ANVISA; Rev. Saúde Pública 2006, 40, 361.

200. USDA; Pesticide Data Program to Release, Food and Society, 2004. http://www.usda.gov/wps/portal/usdahome, acessada em Julho 2008.

201. ANVISA; Programa de Análise de Resíduos de Agrotóxicos em Alimentos (PARA). Minuta de Nota Técnica para divulgação dos resultados do PARA, 2008.

202. Ministério da Saúde, ANVISA, Programa de Análise Resíduos de Agrotóxicos em Alimentos - PARA; Resultado do monitoramento de agrotóxico em alimentos pela ANVISA, 2007.

203. Picó, Y.; Font, G.; Moltó, J. C.; Mañes, J.; J. Chromatogr., A 2000, 882, 153.

204. Botton, M.; comunicação pessoal. Empresa Brasileira de Pesquisa Agropecuária - EMBRAPA Uva e Vinho, Bento Gonçalves, RS, 2007.

205. Caldas, E. D.; Souza, L. C. K.; Food Addit. Contam. 2004, 21, 1057.

206. Caldas, E. D.; Tressou, J.; Boon, P. E.; Food Chem. Toxicol. 2006, 44, 1562.

207. Sharma, I. D.; Nath, A.; Int. Soc. Horticultural Sci., Acta Horticulturae 2006, 696, 1 